\title{
Aß25-35 induction of necroptosis through activation of the RIPK1/RIPK3 and RIPK1/ERK1/2 signaling pathways is attenuated with DHA treatment in THP-1 monocytes
}

\section{Shiqi Yuan}

Department of Neurology, The Third Affiliated Hospital of Southern Medical University https://orcid.org/0000-0002-2794-2546

Huan Li

Department of Neurology, The Third Affiliated Hospital of Southern Medical University Canhong Yang

Department of Neurology,The Third Affiliated Hospital of Southern Medical University

\section{Wenyi Xie}

Department of Neurology, The Third Affiliated Hospital of Southern Medical University

\section{Yuanyuan Wang}

Department of Neurology, The third Affiliated of Southern Medical University

Jiafa Zhang

Department of Neurology,The Third Affiliated Hospital of Southern Medical University

\section{Zibo Cai}

Department of Neurology,The Third Affiliated Hospital of Southern Medical University

\section{Zhenlin Mao}

Department of Neurology,The Third Affiliated Hospital of Southern Medical University

\section{Weibing Xie}

Judicial Identification Center of Southern Medical University

Tianming Lü ( $\square$ lutianming@139.com)

https://orcid.org/0000-0003-0747-4228

\section{Research}

Keywords: Alzheimer's disease, Aß25-35, THP-1 cells, Docosahexaenoic acid (DHA), Necroptosis, MAPK, NF-kB

Posted Date: December 3rd, 2019

DOl: https://doi.org/10.21203/rs.2.17970/v1 
License: (c) (i) This work is licensed under a Creative Commons Attribution 4.0 International License. Read Full License 


\section{Abstract}

Background: Monocytes play a crucial role in Alzheimer's disease (AD), and docosahexaenoic acid (DHA) treatment has a neuroprotective effect for many neurodegenerative diseases. However, mechanisms that regulate monocyte and $A \beta$ protein interaction in $A D$ and the effects of DHA on monocytes in the context of $A D$ are not fully understood.

Methods: The experiments were designed to further explore possible mechanisms of interaction between monocytes and $A \beta$ plaques. Another objective of this study was to investigate a potential mechanism for $A \beta$-mediated regulation of necroptosis and the MAPK and NF-kB signaling pathways, as well as how these pathways might be modulated by DHA in human THP-1 monocytes. We also investigated whether DHA indirectly suppressed THP-1 cell-mediated neuronal activation. We used cell viability and cytotoxicity assays, flow cytometry, transwell migration assays, and Western blotting to perform our study.

Results: Our findings indicate that Aß25-35 regulates two aspects of THP-1 cells necroptosis. We also observed that increased resistance to apoptosis in THP-1 cells that is correlated with THP-1 monocyte differentiation. Our results also indicated that DHA treatment restored migration of THP-1 monocytes that had been treated with A $325-35$. Pre-treatment of THP-1 monocytes with DHA effectively inhibited A $\beta$ induced activation and markedly suppressed protein expression of TNF-aXIL-1 $\beta$ and IL-6. We also found that THP-1 cell necroptosis was induced by A $325-35$ through modulation of RIPK1/RIPK3 and phosphorylation status of ERK1/2 and could be attenuated by DHA treatment.

Conclusion: A 25 -35-mediated induction of necroptosis through activation of the RIPK1/RIPK3 and RIPK1/ ERK1/2 signaling pathways in THP-1 monocytes can be attenuated by DHA treatment, indicating that DHA treatment could be a promising new therapy for AD management.

\section{Introduction}

Alzheimer's disease (AD), the leading cause of dementia, encompasses a range of neurological symptoms, including memory loss and cognitive impairment [1]. The neuropathological changes of Alzheimer disease (AD) consist of abundant amyloid plaques and neurofibrillary tangles, neuropil threads, and dystrophic neurites containing hyperphosphorylated tau [2,3]. AD is likely caused at least in part by an imbalance between amyloid- $\beta(A \beta)$ protein production and clearance, which leads to $A \beta$ accumulation in the central nervous system (CNS). The main pathways that act to clear excess $A \beta$ are proteolytic degradation, transcytosis across the blood-brain barrier (BBB), and perivascular lymphatic drainage $[4,5]$.

Monocytes play a crucial role in $A D$, given that monocyte-derived perivascular macrophages efficiently phagocytose accumulations of $A \beta[6]$. A $\beta$ accumulation can stimulate the RAGE and PECAM- 1 receptors to promote the migration of monocytes along human brain endothelial cells [7]. Using live intravital twophoton microscopy in triple-transgenic APPswe/PS1+/-/Cx3cr1 gfp/+ mice, Michaud et al. demonstrate that patrolling monocytes are attracted to and crawl onto the luminal walls of $A \beta$-positive veins. 
Furthermore, they report the presence of crawling monocytes carrying $A \beta$ in veins that are able to circulate back into the bloodstream [8]. Compared to monocytes, microglia have a limited ability to degrade $A \beta$ plaques, resulting from the low activity levels of several microglial lysosomal enzymes [9]. Patrolling monocytes may therefore play a more important role in $A \beta$ clearance, and further increasing vascular $A \beta$ clearance via patrolling monocytes could have significant impact on AD. Reducing the migration, phagocytosis, or number of mononuclear cells in transgenic AD mice is detrimental, whereas treatments with compounds that increase the number and phagocytic activity of mononuclear cells are generally beneficial[10]. Finding a way to promote effective monocyte-mediated $A \beta$ protein clearance while avoiding the activation of proinflammatory and neurotoxic pathways is an attractive approach for treating $A D$ [11] The experiments in this current study were designed to further explore possible mechanisms of interaction between monocytes and $A \beta$ protein.

Studies have shown that the neurotoxicity directly or indirectly induced by accumulation of $A \beta$ protein is a primary cause of neuron injury in AD. Kwon et al. have shown drug treatment can directly ameliorate the toxic effects $A \beta$ accumulation causes in neurons $[12,13]$. $A \beta$ accumulation can also indirectly exert a toxic effect on neurons through targeting microglial cells, so protection of microglial cells is also important for alleviating $A D$ symptoms $[14,15]$. Further studies are necessary to understand the mechanism by which $A \beta$ plaques interact with monocytes to exert neurotoxic effects.

Docosahexaenoic acid (DHA) is an essential omega-3 polyunsaturated fatty acid (PUFA) found predominantly in marine products. Preclinical and clinical studies have demonstrated that DHA exerts a neuroprotective effect in the context of several neurodegenerative diseases, including $A D$, resulting mostly from the antioxidant and anti-inflammatory properties of DHA and its ability to activate several other signaling pathways[16]. Given that monocytes are involved in the clearance of $A \beta$ plaques, additional studies are needed to elucidate a potential mechanism for how DHA might be involved in promoting monocyte-mediated clearance of $A \beta$ plaques.

Necroptosis is a lytic cell death program defined by activation of the receptor interacting protein kinase-1 (RIPK1) and RIPK3 to form an oligomeric "necrosome," which leads to the phosphorylation and activation of the effector protein pseudokinase mixed lineage kinase domain-like (MLKL)[17].This necroptosis pathway is implicated in several neurodegenerative diseases [18]. NF-KB plays a key role in modulating immune and inflammatory responses, while mitogen-activated protein kinases (MAPKs) (P38, ERK1/2) are key regulators of a variety of cellular functions including cell survival, apoptosis and cellular responses to inflammation[19, 20]. Upon TNF binding to its receptor to form Complex I, RIPK1 can interact with Complex I, which activates the MAPK signaling cascade and the transcription factor NF-KB [21]. Therefore, we further investigated a possible mechanism for $A \beta$-mediated regulation of necroptosis, MAPK and NF-kB signaling pathways in monocytes.

The experiments in this study were designed to further explore possible mechanisms by which monocytes and $A \beta$ protein might interact. Another objective of this study was to investigate a possible mechanism for $A \beta$-mediated regulation of necroptosis, MAPK and NF-kB signaling pathways in vitro in 
human THP-1 monocytes. We also investigated the role of DHA in modulating A $\beta$-regulated signaling pathways and whether DHA indirectly suppressed THP-1 cell-mediated neuronal activation.

\section{Methods}

\section{Materials}

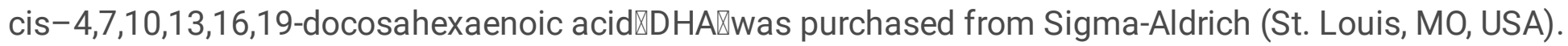
Neurobasal medium, B-27 supplement, and penicillin, DMEM medium, 1640 medium, and fetal bovine serum (FBS) were purchased from Gibco (Grand Island, NY, USA). CCK8, Necrostatin-1 (NEC-1), GSK872 were purchased from MedChem Express (New Jersey, USA). Anti-RIPK3 (A5431), MLKL (A5579), TNF (A0277), IL-6(A0286), and IL-1 $\beta(A 1112)$ antibodies were purchased from ABclonal (Wuhan, China). Pp44/42 MAPK (ERK1/2), p44/42 MAPK(ERK1/2), NF-kB p65, NF-kB p65, p-p38 MAPK and p38 MAPK were purchased from Cell Signaling Technology Company (Danvers, MA, USA). GAPDH antibody and Horseradish peroxidase-conjugated secondary antibodies were purchased from Proteintech (Chicago,

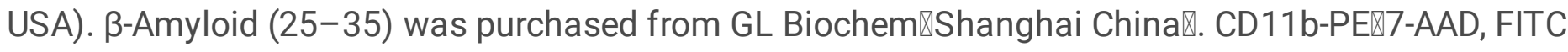
Annexin V Apoptosis Detection Kit I were purchased from BD Pharmingen $₫$ San Diego, CA, USA) $\mathbb{}$ (CytoTox

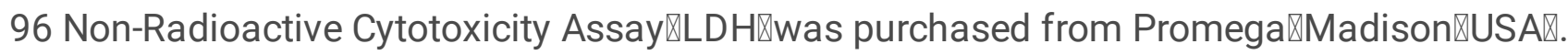

\section{Preparation of A $\mathrm{B25}-35$ peptide}

A $325-35$ was dissolved in sterile distilled water at a concentration of $1 \mathrm{nM}$ and then filtered through a $0.22 \mu \mathrm{m}$ filter. $\mathrm{A} \beta 25-35$ was aggregated during a 7 day incubation period at $37^{\circ} \mathrm{C}$ and then stored in a $-20^{\circ} \mathrm{C}$ freezer for later use.

\section{Preparation of DHA}

DHA was dissolved in DMSO at a concentration of $10 \mathrm{nM}$ and then filtered through a $0.22 \mu \mathrm{m}$ filter. This DHA solution was stored in a $-80^{\circ} \mathrm{C}$ freezer for later use. The control group was added with the same concentration DMSO.

\section{Cell culture conditions}

The human THP-1 cell line was a gift from NanFang Hospital of Southern Medical University and was cultured in RPMI 1640 medium supplemented with $10 \% \mathrm{FBS}$ at $37^{\circ} \mathrm{C}$ in a humidified incubator $(5 \% \mathrm{CO} 2$, $95 \%$ air). The THP-1 cells $₫ 10 \times 104$ cells/ml $\varangle$ were pretreated with DHA in $0 \%$ FBS for 1,3 , or 5 days. Conditioned media (CM) from each THP-1 plate was then collected and stored at $-80^{\circ} \mathrm{C}$ for later use.

The SY5Y cell line was a gift from The Judicial Identification Center of Southern Medical University and was cultured in the same growth conditions as the THP-1 cell line. SY5Y cells were treated with Aß25- 
35 aggregates and the conditioned media (CM) collected from plates of THP-1 cells.

Primary cortical neurons were prepared from embryonic day 16-18 (E16-18) C57BL/6 mice, which were purchased from the Experimental Animal Center of Southern Medical University. All animal experiments were approved by the Institutional Animal Care and Use Committee of Southern Medical University in accordance with the guidelines of the Institutional Animal Care and Use Committee of the National Institutes of Health and the Guide for the Care and Use of Laboratory Animals. The cerebral cortices of E16-18 embryos were dissected under bacterial conditions and placed in sterile PBS. The cerebellum, hippocampus and medulla were removed and the cortex was isolated; meninges and blood vessels were then removed. Brain tissue was minced with a razor blade and then digested in $0.25 \%$ trypsin at $37^{\circ} \mathrm{C}$ for 6 min. Addition of complete 10\% FBS medium was used to terminate digestion. Cell suspensions were then filtered using a $70 \mu \mathrm{m}$ cell filter. The filtered cell suspension was collected in a $15 \mathrm{ml}$ conical and centrifuged at $1000 \mathrm{rpm}$ for $5 \mathrm{~min}$. The supernatant was discarded and the cells were seeded onto Llysine coated plates. Initial administration of a modified neurobasal media (B27 supplement, 1\% Lglutamine, $0.05 \%$ glutamate, and $1 \%$ penicillin/streptomycin) was followed by media changes every other day using a standard neurobasal media (B27 supplement, 1\% L-glutamine, 1\% penicillin/streptomycin). After 5 days of culture, primary cortical neurons were stimulated with addition of varying concentrations of AB25-35 or CM obtained from THP-1 monocytes.

\section{Detection of cell viability using cell counting kit-8 (CCK8)}

Cells for each treatment group were counted and seeded in 96-well plates at $100 \mu \mathrm{l} /$ well in quintuplicate for each treatment group. After treatment for the appropriate time, $10 \mu \mathrm{l}$ of CCK8 were added and the absorbance at $450 \mathrm{~nm}$ was measured using a plate reader.

\section{Detection of cytotoxicity via LDH release}

Cytotoxicity was monitored using the CytoTox 96 Non-Radioactive Cytotoxicity Assay (LDH assay) kit, which quantifies the amount of lactate dehydrogenase (LDH) released from cells into the media. The assay was performed according to the manufacturer's protocol. Briefly, following treatment, the culture plate was centrifuged at $250 \times \mathrm{g}$ in a high-efficiency multi-purpose centrifuge for $5 \mathrm{~min}, 50 \mu \mathrm{l}$ of supernatant was pipetted into a new 96-well plate, and LDH activity determined was based on absorbance readings at $490 \mathrm{~nm}$. The amount of LDH release is used to calculate cytotoxicity. Three replicates were used for each experiment.

\section{Measure of apoptosis/ necrosis and CD11b expression by flow cytometry}

Flow cytometry experiments were done using the FITC Annexin V Apoptosis Detection Kit I (BD Pharmingen) according to the manufacturer's protocol. After stimulating the various cell groups, 6-well 
plates of THP-1 cells were centrifuged at $1000 \mathrm{rpm}$ for 5 min twice with gentle PBS wash steps between spins. $500 \mu \mathrm{l}$ of binding solution was then added to gently suspend the cells. After waiting $10 \mathrm{~min} \varangle 20 \mu \mathrm{l}$ of CD11b- PE, $5 \mu$ l of Annexin V-FITC stain, and $5 \mu$ of 7-AAD was added to each well and gently mixed. The plate was then incubated at room temperature $\left(20-25^{\circ} \mathrm{C}\right)$ in the dark for $15 \mathrm{~min}$. The cells were then analyzed using a flow cytometer. BD FACSDiva 8.0.1 was used to analyze cell apoptosis/necrosis and CD11b expression.

\section{Transwell migration assays}

THP-1 cells were collected by centrifugation at $1,200 \times \mathrm{g}$ for $5 \mathrm{~min}$ at room temperature and resuspended in RPMI 1640 was seeded into the upper chamber $(3450,5.0 \mu \mathrm{m}$ porous polycarbonate membrane, Corning, USA), and the lower chamber was coated with $600 \mu \mathrm{l}$ of RPMI 1640 media with $10 \%$ FBS. After $12 \mathrm{~h}$ of culture, the transwell chamber membranes were cleaned and fixed with $4 \%$ paraformaldehyde for 30 min and then stained with $1 \%$ crystal violet for 20 min. Cell counting was carried out using a microscope (100x) and was performed in triplicate.

\section{Western blot analysis}

The protein concentration of each sample was determined using a dye-binding protein assay kit (Bioimage, San Diego, USA), and the protein was stored at $-20^{\circ} \mathrm{C}$ for later use. Protein samples were subjected to sodium dodecyl sulfate polyacrylamide gel electrophoresis (SDS-PAGE), after which the protein was transferred to a PVDF membrane (Millipore Corporation, Billerica, MA 01821, USA). The membrane was blocked with $5 \%$ bovine serum albumin (Pharmingen San Diego, CA, USA) for $1 \mathrm{~h}$ at room temperature, followed by overnight incubation in primary antibody at $4^{\circ} \mathrm{C}$, followed by incubation with a horseradish peroxidase-coupled secondary antibody at room temperature for $1 \mathrm{~h}$. Protein bands were visualized with a chemiluminescence detection kit (Beyotime, Guangzhou, China).

\section{Statistical analysis}

Spss23.0 software was used for statistical analysis of all data obtained. For experiments comparing multiple groups, statistical analysis was done using Tukey's method with one-way ANOVA. For experiments comparing two groups, statistical analysis was done using a $t$ test. Data are shown as averages $\pm S D$, and differences are considered to be significant at $p<0.05$.

\section{Results}

\section{A $25-35$ have two aspects of THP-1 cells viability}

To investigate the effect of stimulating THP-1 monocytes with A $325-35$, we treated cells with varying concentrations of $\mathrm{A} \beta 25-35$ for different amounts of time and examined cell viability and cytotoxicity. 
These experiments indicated that THP-1 cells increased viability compared to control when A $325-35$ concentrations were lower than $10 \mu \mathrm{M}$. However囚after seeing a gradual increase in viability up to $10 \mu \mathrm{M}$ concentrations, THP-1 cells had decreased viability with prolonged A $325-35$ stimulation (Fig. 1A-1C).

The CCK8 assay measures cell viability based on intact mitochondrial function, and the LDH release assay determines cytotoxicity based on cell membrane integrity. Therefore, to determine if A $325-35$ stimulation has cytotoxic effects on THP-1 monocytes, we measured the LDH content of cell supernatants under the same conditions used for viability assays (Fig. 2A-2C). The results of the LDH assay followed similar trends to those observed with the CCK8 assay. Therefore, stimulation with A $325-$ 35 for a relatively short time or with a low concentration has minimal cytotoxic effects on THP-1 cells and promotes viability, and $A \beta 25-35$ have two aspects of THP- 1 cells viability.

\section{A 25-35 treatment influences THP-1 cell apoptosis (necrosis) and differentiation}

One of the most striking features that macrophages acquire as a result of differentiation is increased resistance to apoptosis[22]. To further explore how A 25-35 treatment influences THP-1 cells, we wanted to determine whether apoptosis (necrosis) and THP-1 cell differentiation might be involved. Therefore, THP- 1 cells were treated with A $325-35$ for 3 days, and then analyzed by flow cytometry with Annexin V-FITC, 7AAD and the antigen CD11b (a surface marker for THP-1 cell differentiation [22] $ه$ Figure $3 A$ shows the gating scheme used: normal cells (Q3), early apoptotic cells (Q4), late apoptotic /necrotic cells (Q2), and CD11b PE-A (cell expression after differentiation). Treatment with low concentrations of A $25-35(0-10 \mu \mathrm{M})$ significantly protected THP-1 cells from apoptosis (necrosis), but treatment with high concentrations (10-40 $\mu \mathrm{M}$ ) resulted in increased apoptosis (necrosis) (Fig. 3B). Simultaneously, compared with the control group $(0 \mu \mathrm{M} A \beta), C D 11 \mathrm{~b}$ expression increased with $A \beta 25-35$ concentration (Fig. 3C).

Taken together. The increased apoptotic resistance is generated at the same time as the cytotoxic effect. Treated with low concentration of $A \beta 25-35$, the increased resistance to apoptosis is dominated, conversely, the advantage of cytotoxic effect is highlighted. These results indicate $A \beta 25-35$ regulates two aspects of THP-1 cells necroptosis, and the increased resistance to apoptosis is correlated with THP-1 monocyte differentiation.

\section{DHA inhibits A $\beta$-induced activation of THP-1 cells}

To investigate whether DHA treatment is cytotoxic to THP-1 cells, we repeated the CCK8 viability assay with THP- 1 cells treated with varying concentrations of DHA for $1 d, 3 d$ and $5 d$. This experiment showed that DHA has a positive effect on THP-1 cell viability at a range of concentrations between 0.0625 and $1 \mu \mathrm{M}$ (Fig. 4). 
To determine how DHA affects viability of A $325-35$ treated THP- 1 cells, THP- 1 cells were pre-treated with or without various concentrations of DHA in RPMI 1640 with $0 \%$ FBS for $24 \mathrm{~h} \nabla$ followed by treatment

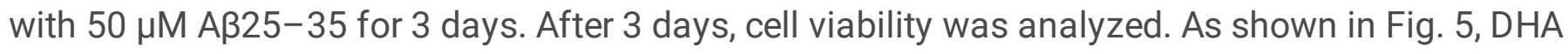
pretreatment significantly inhibited the activation of THP-1 cells induced by A $325-35$ in a concentrationdependent manner.

\section{DHA indirectly suppresses THP-1 cell-mediated neuronal activation}

Substantial evidence suggests that DHA can directly reduce AB-induced activation[13, 23]. We therefore tested whether pre-treatment with low concentrations $(0.5,1 \mu \mathrm{M})$ of DHA in RPMI 1640 with $0 \%$ FBS for $24 \mathrm{~h}$ could reduce A $325-35$-mediated activation of neurons and SY $5 Y$ cells. Using the CCK8 assay as a

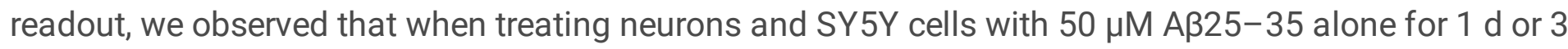
d, viability did not significantly decrease until day 3 (Fig. 6, Fig. 7). Furthermore, low concentrations of DHA did not inhibit A $\beta$-induced activation of neurons and SY5Y cells, similar to previous findings[23].

We next investigated whether $A \beta$ aggregates could exert their effect on neuronal cells through THP-1 cells and how DHA might regulate this process. THP-1 cells were pre-treated with or without various

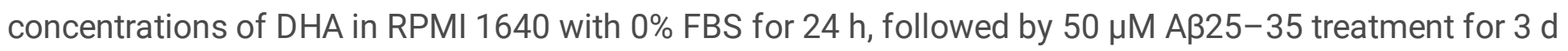
(the media was not changed). CM from each THP-1 cell treatment group was collected and used to stimulate neurons for $3 \mathrm{~d}$ or $5 \mathrm{~d}$. Using the CCK8 assay as a readout, CM treated with $A \beta$ alone (AB-CM) induced neuronal toxicity to a much greater extent than the vehicle control (control $\mathrm{CM}$ ), while $\mathrm{CM}$ from THP-1 cells that were pretreated with DHA prior to $A \beta$ treatment (DHA+A $\beta-C M$ ) induced significantly less cytotoxicity in cortical neurons compared with A $\mathrm{A}-\mathrm{CM}$ (Fig. 8B). Interestingly, compared to cells directly treated with $50 \mu \mathrm{M} \mathrm{A \beta 25-35}$ for 3 days (Fig. 6B), less cytotoxicity was observed in cortical neurons treated with $A \beta-C M$ for 3 days (Fig. $8 A$ ). Taken together, these findings indicate that THP-1 cells played an important role in $A \beta$ clearance and DHA treatment can indirectly suppress THP- 1 cell-mediated neuronal activation.

\section{DHA restored the THP-1 monocytes migration treated with A $325-35$}

To investigate whether DHA treatment could modulate the A $325-35$-induced THP-1 monocytes migration phenotype $\triangle \mathrm{THP}-1$ cells were pre-treated with or without low concentrations $(0.5,1 \mu \mathrm{M})$ of $\mathrm{DHA}$ in RPMI 1640 with $0 \%$ FBS for $24 \mathrm{~h}$, followed by $50 \mu \mathrm{M}$ AB25-35 treatment for 3 days. A transwell system was used to test the migratory ability of THP-1 cells collected from different treatment groups. As shown in Fig. 9, the number of migratory THP-1 monocytes after $12 \mathrm{~h}$ were significantly decreased in $A \beta$ group compared to control. In comparison to $A \beta$ group, the number of migratory cells in the A $\beta+D H A$ groups was significantly higher. Therefore, the results indicate that DHA pre-treatment inhibits the anti-migratory effect exerted by A $325-35$ on THP-1 monocytes. 


\section{DHA suppresses $A \beta$-induced expression of pro-inflammatory cytokines in THP-1 cells}

TNF-a $\mathbb{Z} \mathrm{IL}-1 \beta$, and IL -6 are the primary pro-inflammatory cytokines in the inflammatory response cascade. To investigate how DHA treatment affects $A \beta$-induced expression of pro-inflammatory cytokines, the protein expression levels of TNF-aXIL $-1 \beta$ and IL-6 in DHA and A $\beta 25-35$ treated THP- 1 cells were quantified. TNF-aXIL-1 $\beta$, and IL -6 expression all increased significantly in THP- 1 cells after treatment with $50 \mu \mathrm{M} \mathrm{A \beta 25-35}$ alone (Fig. 10). However, when THP-1 cells were treated with DHA prior to treatment with $A \beta 25-35$, expression of these pro-inflammatory cytokines was notably decreased compared to $50 \mu \mathrm{M}$ A $325-35$ treatment alone. These results demonstrate that DHA treatment in THP-1 cells suppresses $A \beta$-induced protein expression of TNF-aXIL-1 $1 \beta$ and IL -6 .

\section{DHA inhibits AB25-35-induced necroptosis of THP-1 monocytes}

We next investigated whether $A \beta$-mediated regulation of necroptosis could be modulated by DHA in human THP-1 monocytes. Western blotting for key necroptosis proteins revealed that cells pre-treated with DHA had lower expression levels of RIPK1, RIPK3, and MLKL compared to cells treated with only A $325-35$ (Fig. 11). Therefore, our resulted indicate that DHA treatment inhibits A $325-35$-induced necroptosis of THP-1 monocytes Aß25-35.

\section{DHA attenuates A $325-35$-induced necroptosis of THP-1 monocytes via the RIPK1/RIPK3 signaling pathway}

Necroptosis is a lytic cell death program defined by activation of the receptor interacting protein kinase-1 (RIPK1) and RIPK3 to form an oligomeric "necrosome," which leads to the phosphorylation and activation of the effector pseudokinase mixed lineage kinase domain-like (MLKL). To further investigate whether DHA could attenuate A $325-35$-induced necroptosis of THP-1 monocytes via the RIPK1/ RIPK3 signaling pathway, we tested whether NEC-1 (RIPK1 inhibitor[24]) could inhibit Aß-induced activation of THP-1 cells. Viability of THP-1 cells was determined after cultures were pre-treated with or without various

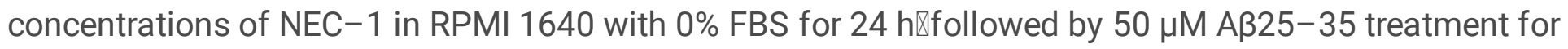
3 day. NEC-1 pre-treatment significantly inhibited $A \beta 25-35$-induced activation of THP- 1 cells in a concentration-dependent manner (Fig. 12A). The $10 \mu \mathrm{M} \mathrm{NEC-1} \mathrm{concentration} \mathrm{was} \mathrm{chosen} \mathrm{for} \mathrm{all}$ subsequent experiments.

THP- 1 cells were pre-treated with or without NEC-1 and DHA in RPMI 1640 with $0 \%$ FBS for $24 \mathrm{~h} \nabla$ followed by $50 \mu \mathrm{M}$ Aß25-35 treatment for 3 days. Western blot analysis was then used to determine RIPK3 expression levels. Expression of RIPK3 was suppressed by NEC-1 treatment in the presence or absence of DHA compared when compared with AB25-35 treatment (Fig. 12B-C). This finding indicates that DHA could prevent $A \beta$-induced necroptosis of THP-1 cells via the RIPK1/RIPK3 signaling pathway. 


\section{DHA suppresses ERK1/2 signaling activated $A \beta 25-35$ but does not affect $\mathrm{p} 38$ or NF-KB/p65 signaling}

NF-KB signaling plays a key role in immune and inflammatory responses, while MAPK kinases ( $\mathrm{p} 38$, ERK1/2) are key regulators of a variety of cellular functions, including cell survival, apoptosis and inflammation response $[19,20]$. We tested whether DHA treatment modulated $A \beta$-mediated regulation of MAPK and NF-KB signaling in human THP-1 monocytes. THP-1 cells were pretreated with or without varying concentrations of DHA in RPMI 1640 with $0 \%$ for 1 day prior to incubation with $50 \mu \mathrm{M} \mathrm{A} 325-35$ for another 3 days. Compared to the $0 \mu \mathrm{M}$ Aß25-35 treatment group, the phosphorylation levels of p38 and ERK1/2 were significantly increased in the $50 \mu \mathrm{M} \mathrm{A \beta 25-35}$ treatment group (Fig. 13). However,

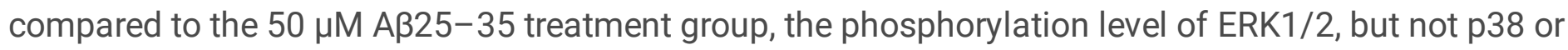
p65, was decreased in the A $\beta+D H A$ treatment groups. Taken together, our results show that DHA treatment suppresses A $325-35$-induced ERK1/2 signaling in THP-1 cells, but does not affect p38 or NF$\mathrm{kB} / \mathrm{p} 65$ signaling.

\section{DHA targets RIPK1 to inhibit ERK1/2 phosphorylation in THP-1 cells treated with AB25-35}

Increasing evidence indicates that RIPK1 can regulate cell survival via activation of the ERK $1 / 2$ signaling pathway $[25,26]$. Therefore, THP- 1 cells were pre-treated with or without NEC-1 and DHA in RPMI 1640 with $0 \%$ FBS for $24 \mathrm{~h}$, followed by treatment with $50 \mu \mathrm{M} \mathrm{A \beta 25-35}$ for 3 days. Western blotting was used to determine the phosphorylation status of ERK1/2. As shown in Fig. 14, phosphorylation of ERK1/2 was suppressed by the RIPK1 inhibitor NEC-1 in the presence or absence of DHA compared with A $325-35$ treatment. Hence, our results indicate that DHA treatment inhibits ERK1/2 phosphorylation via RIPK1 in THP-1 cells treated with A $25-35$.

\section{Discussion}

Monocytes play a crucial role in $A D$, as monocyte-derived perivascular macrophages efficiently execute $A \beta$ phagocytosis $[6,27]$. The mechanism connecting brain amyloid accumulation and monocyte degeneration is multifactorial. Deposition of $A \beta$ aggregates in blood vessels can directly damage the vessel wall and allow more monocytes to pass through the parenchyma[28].Toll-like receptor 2 (TLR2) and Toll-like receptor 4 (TLR4) were shown to be indirectly involvedin A $\beta$ phagocytosis through the formation of a receptor complex with CD14 and the subsequent activation of monocytes[29]. A $\beta$-induced migration of monocytes across human brain endothelial cells involves both RAGE and PECAM-1[7]. Increasing vascular $A \beta$ clearance through the activity of patrolling monocytes could help ameliorate $A D$ symptoms.In this regard, reduction of the migration, phagocytosis, or number of mononuclear cells in transgenic AD mice is detrimental, whereas compounds that increase their number and phagocytic activity are generally beneficial [10]. Oligomeric amyloid- $\beta(1-42)$ is known to induce THP-1 monocyte adhesion and maturation [30], but these findings have not been further expored. Therefore, our 
experiments were designed to further explore possible mechanisms of the interaction between monocytes and $A \beta$. We demonstrated that $A \beta 25-35$ influences THP- 1 cell viability, as confirmed by LDH and CCK8 assays. Macrophages are known to become more resistant to apoptosis as a result of differentiation [22, 31], Interestingly, by flow cytometry analysis, we observed that increased apoptotic resistance develops in correlation with trends in A $25-35$-mediated THP- 1 cell cytotoxicity. When THP- 1 cells are treated with low concentrations of $A \beta 25-35$, we observed increased resistance to apoptosis, conversely, the advantage of cytotoxic effect is highlighted. Taken together, our results indicate that A $\beta 25-35$ had a dual effect on THP- 1 cell apoptosis (necrosis), and increased THP-1 cell resistance to apoptosis is associated with THP-1 monocyte differentiation.

Studies have shown that DHA has a neuroprotective effect in many neurodegenerative diseases through its antioxidant and anti-inflammatory properties and its ability to activate various cell signaling pathways[16, 32]. Microglial cells and macrophages are key cells in the immune system, and they play important roles in CNS repair and regeneration[33]. In addition to their neuroprotective roles, microglial cells and macrophages are also the major producers of proinflammatory cytokines, such as TNF- $\mathrm{a}, \mathrm{IL}-1 \beta$, and IL-6, which can greatly inhibit brain repair and neurogenesis[34]. Here, we found that low concentrations of DHA were insufficient to inhibit A $\beta$-induced activation of neurons and SY5Y cells but could indirectly suppress THP-1 cell-mediated neuronal activation effectively. Moreover, we found that pre-treatment with DHA effectively attenuated $A \beta$-induced activation of THP-1 monocytes and markedly suppressed expression of TNF- $\alpha, I L-1 \beta$, and IL -6 . Interestingly, our results also indicated that DHA treatment restored migration of THP-1 monocytes that had been treated with A $\beta 25-35$.

Necroptosis, a form of regulated necrotic cell death mediated by RIPK1, RIPK3, and MLKL (mixed-lineage kinasedomain-like pseudokinase) [35], can be activated under apoptosis-deficient conditions [17, 36]. Substantial evidence indicates that necroptosis is involved in AD pathogenesis [37, 38]. RIPK1, RIPK3, and MLKL expression were all found to be increased in the brains of individuals with $A D$ individuals as well as in the brains of $A D$ animal models [39]. Therefore, we investigated whether $A \beta$ aggregates or $D H A$ mediated regulation of necroptosis in human THP-1 monocytes. Our resulted indicate that A $\beta 25-35$ treatment induced necroptosis of THP-1 monocytes that could be attenuated with DHA treatment.

NEC-1 (necrostatin-1), a specific inhibitor of RIPK1, prevents cell necroptosis[40, 41]. Our results showed that NEC-1 pre-treatment significantly inhibited the activation of THP-1 cells induced by A $325-35$ in a concentration-dependent manner. Additionally, expression of RIPK3 was suppressed by NEC- 1 treatment in the presence or absence of DHA compared with $A \beta 25-35$ treatment. This finding suggests that DHA treatment could attenuate $A \beta 25-35$-induced necroptosis of THP-1 monocytes via modulation of the RIPK1/RIPK3 signaling pathway.

The mitogen-activated protein kinases (MAPKs) in mammals include c-Jun NH2-terminal kinase (JNK), p38 MAPK, and extracellular signal-regulated kinase (ERK). These enzymes are serine-threonine protein kinases that regulate various cellular activities including proliferation, differentiation, apoptosis or cell survival, inflammation, and innate immunity $[42,43]$. Impaired signaling pathways contribute to the 
pathology of many human diseases, including cancer and neurodegenerative diseases such as $A D$, Parkinson's disease, and amyotrophic lateral sclerosis [44, 45]. Subsequent studies have shown that NF$\mathrm{KB}$ is a ubiquitously expressed dimeric transcription factor involved in cellular processes such as inflammation, adhesion, proliferation, differentiation, apoptosis, and oncogenesis [46]. This family of transcription factors also plays an important role in nervous system development and function [47]. We explored whether $A \beta$ aggregates or DHA regulate the MAPK and NF-KB signaling pathways in human THP-1 monocytes. Our findings indicate that A $25-35$ treatment activated the ERK $1 / 2$ and $p 38$ signaling pathways, but not NF-KB/p65 signaling, while pre-treatment with DHA followed by A $325-35$ treatment suppressed only ERK $1 / 2$ signaling.

Several studies have shown that RIPK1 activates MAPKs such as p38, JNK, and ERK during apoptosis following TNF-a treatment[21, 25, 48] \and that RIPK1 plays an important role at the crossroads of a cell's decision to live or die [49]. Our study revealed that ERK1/2 phosphorylation is suppressed by NEC- 1 in the presence or absence of DHA treatment when compared with A $325-35$ treatment. Our findings indicate that DHA treatment could inhibit ERK1/2 phosphorylation via RIPK1 in THP-1 cells treated with A 25-35. Previous work has demonstrated that ERK activation plays a critical role in necroptosis, and the RIPK1/ERK signaling pathway may present a new therapeutic avenue for treatment of ischemiareperfusion injury and neurodegenerative diseases where necroptotic cell death is implicated[50]. However, the relationship between necroptotic signaling pathways and ERK1/2 is incompletely understood and requires further exploration. Since this study relied on an in vitro model using THP-1 cells instead of primary monocytes, additional studies with primary monocytes and an in vivo model are needed to confirm and extend our findings.

\section{Conclusion}

Our findings indicate that $A \beta 25-35$ regulates two aspects of THP-1 cells necroptosis. We also observed that increased resistance to apoptosis in THP-1 cells that is correlated with THP-1 monocyte differentiation. Our results also indicated that DHA treatment restored migration of THP-1 monocytes that had been treated with $A \beta 25-35$. We found that pre-treatment with DHA effectively inhibited A $B$ induced activation of THP-1 monocytes and markedly suppressed protein expression of TNF- $a$, IL-1 $\beta$, and IL-6. DHA treatment can attenuate necroptosis via modulation of the RIPK1/RIPK3 signaling pathway and the phosphorylation status of ERK1/2 in THP-1 monocytes. Our study offers insight into the anti-inflammatory and anti-necroptotic properties of DHA. Therefore, our findings suggest that DHA might could have therapeutic potential for use in $A D$ management.

\section{Abbreviations}

AD,Alzheimer's disease;DHA, Docosahexaenoic acid; MAPKs,mitogen-activated protein kinases;NF-KB, nuclear transcription factor-kappa B; TNF-a, tumor necrosis factor-alpha; IL-6, interleukin-6; IL-1 $\beta$, interleukin-1 beta; iNOS, inducible NO synthase; MLKL, mixed lineage kinase domain-like; NEC1 , necrostatin-1. 


\section{Declarations}

\section{Acknowledgements}

Judicial Identification Center of Southern Medical University Provides Experimental equipment and technical guidance.

\section{Funding}

This work was supported by grants from Natural Science Foundation of Guangdong Province (Grant No. 2017A030313461) \Science and Technology Project of Guangzhou City (201803010010), Medical Science and Technology Research Fund of Guangdong Province(A201861), Scientific Research Launch Project of Southern Medical University (PY2017N029) and Health Science and Technology Project of

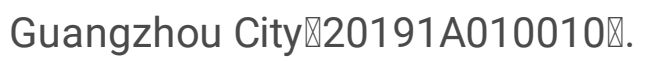

\section{Availability of data and materials}

The datasets used and/or analyzed during the current study are available from the corresponding author on reasonable request.

\section{Authors' contributions}

Tianming Lü conceived and designed the study, Shiqi Yuan and Huan Li performed the experiments and wrote the paper. Wenyi Xie, Yuanyuan Wang, Jiafa Zhang, Zibo cai, and Zhenlin Mao performed part of the experiments. Weibing Xie and Tianming Lü reviewed and edited the manuscript.

\section{Ethics approval and consent to participate}

Not applicable.

\section{Consent for publication}

Not applicable.

\section{Competing interests}

There is no conflict of interest to declare.

\section{References}


1.Winblad B, Amouyel P, Andrieu S, Ballard C, Brayne C, Brodaty H, Cedazo-Minguez A, Dubois B, Edvardsson D, Feldman $\mathrm{H}$, et al: Defeating Alzheimer's disease and other dementias: a priority for European science and society. Lancet Neurol 2016, 15:455-532.

2.Serrano-Pozo A, Frosch MP, Masliah E, Hyman BT: Neuropathological Alterations in Alzheimer Disease. Csh Perspect Med 2011, 1:a6189.

3.Querfurth HW: Alzheimer's Disease (vol 362, pg 329, 2010). New Engl J Med 2011, 364:588.

4.Mawuenyega KG, Sigurdson W, Ovod V, Munsell L, Kasten T, Morris JC, Yarasheski KE, Bateman RJ: Decreased Clearance of CNS -Amyloid in Alzheimer's Disease. Science 2010, 330:1774.

5.Yang C, Huang X, Huang X, Mai H, Li J, Jiang T, Wang X, Lu T: Aquaporin-4 and Alzheimer's Disease. J Alzheimers Dis 2016, 52:391-402.

6. Hawkes CA, McLaurin J: Selective targeting of perivascular macrophages for clearance of beta-amyloid in cerebral amyloid angiopathy. Proc Natl Acad Sci U S A 2009, 106:1261-1266.

7.Giri R, Shen Y, Stins M, Du Yan S, Schmidt AM, Stern D, Kim KS, Zlokovic B, Kalra VK: beta-amyloidinduced migration of monocytes across human brain endothelial cells involves RAGE and PECAM-1. Am J Physiol Cell Physiol 2000, 279:C1772-C1781.

8.Michaud J, Bellavance M, Préfontaine P, Rivest S: Real-Time In Vivo Imaging Reveals the Ability of Monocytes to Clear Vascular Amyloid Beta. Cell Rep 2013, 5:646-653.

9.Majumdar A, Chung H, Dolios G, Wang R, Asamoah N, Lobel P, Maxfield FR: Degradation of fibrillar forms of Alzheimer's amyloid beta-peptide by macrophages. Neurobiol Aging 2008, 29:707-715.

10.Michaud JP, Halle M, Lampron A, Theriault P, Prefontaine P, Filali M, Tribout-Jover P, Lanteigne AM, Jodoin $\mathrm{R}$, Cluff $\mathrm{C}$, et al: Toll-like receptor 4 stimulation with the detoxified ligand monophosphoryl lipid $A$ improves Alzheimer's disease-related pathology. Proceedings of the National Academy of Sciences 2013, 110:1941-1946.

11.Hohsfield LA, Humpel C: Migration of blood cells to $\beta$-amyloid plaques in Alzheimer's disease. Exp Gerontol 2015, 65:8-15.

12.Cheng Y, Li Z, Kardami E, Loh YP: Neuroprotective effects of LMW and HMW FGF2 against amyloid beta toxicity in primary cultured hippocampal neurons. Neurosci Lett 2016, 632:109-113.

13.Kwon SH, Ma SX, Hwang JY, Lee SY, Jang CG: Involvement of the Nrf2/HO-1 signaling pathway in sulfuretin-induced protection against amyloid beta25-35 neurotoxicity. Neuroscience 2015, 304:14-28.

14.Liu N, Zhuang Y, Zhou Z, Zhao J, Chen Q, Zheng J: NF-KB dependent up-regulation of TRPC6 by A in $B V-2$ microglia cells increases COX-2 expression and contributes to hippocampus neuron damage. 
Neurosci Lett 2017, 651:1-8.

15.Zhao Y, Zeng Y, Wu A, Yu C, Tang Y, Wang X, Xiong R, Chen H, Wu J, Qin D: Lychee Seed Fraction Inhibits $A \beta(1-42)$-Induced Neuroinflammation in BV-2 Cells via NF-KB Signaling Pathway. Front Pharmacol 2018, 9.

16.Belkouch M, Hachem M, Elgot A, Lo Van A, Picq M, Guichardant M, Lagarde M, Bernoud-Hubac N: The pleiotropic effects of omega-3 docosahexaenoic acid on the hallmarks of Alzheimer's disease. The Journal of Nutritional Biochemistry 2016, 38:1-11.

17.Linkermann A, Green DR: Necroptosis. New Engl J Med 2014, 370:455-465.

18.Lin Q, Chen P, Wang W, Lin C, Zhou Y, Yu L, Lin Y, Xu Y, Kang D: RIP1/RIP3/MLKL mediates dopaminergic neuron necroptosis in a mouse model of Parkinson disease. Laboratory investigation; a journal of technical methods and pathology 2019.

19.Park S, Hwang J, Jang M, Lee SH, Park J, Han I: A novel caffeic acid-1-piperonylpiperazine hybridization compound HBU-47 inhibits LPS-mediated inflammation in RAW264.7 macrophage cells. Int Immunopharmacol 2014, 19:60-65.

20.Alexa A, Gógl G, Glatz G, Garai Á, Zeke A, Varga J, Dudás E, Jeszenői N, Bodor A, Hetényi C, Reményi A: Structural assembly of the signaling competent ERK2-RSK1 heterodimeric protein kinase complex. Proceedings of the National Academy of Sciences 2015, 112:2711-2716.

21.Newton K: RIPK1 and RIPK3: critical regulators of inflammation and cell death. Trends Cell Biol 2015, 25:347-353.

22.Busca A, Saxena M, lqbal S, Angel J, Kumar A: PI3K/Akt regulates survival during differentiation of human macrophages by maintaining NF-KB-dependent expression of antiapoptotic Bcl-xL. J Leukocyte Biol 2014, 96:1011-1022.

23.Zhang Y, Brown RE, Zhang P, Zhao Y, Ju X, Song C: DHA, EPA and their combination at various ratios differently modulated Aß25-35-induced neurotoxicity in SH-SY5Y cells. Prostaglandins, Leukotrienes and Essential Fatty Acids 2018, 136:85-94.

24.Filipczak PT, Thomas C, Chen W, Salzman A, McDonald JD, Lin Y, Belinsky SA: TSC2 Deficiency Unmasks a Novel Necrosis Pathway That Is Suppressed by the RIP1/RIP3/MLKL Signaling Cascade. Cancer Res 2016, 76:7130-7139.

25.Najjar M, Saleh D, Zelic M, Nogusa S, Shah S, Tai A, Finger JN, Polykratis A, Gough PJ, Bertin J, et al: RIPK1 and RIPK3 Kinases Promote Cell-Death-Independent Inflammation by Toll-like Receptor 4. Immunity 2016, 45:46-59. 
26.Zhang M, Li J, Geng R, Ge W, Zhou Y, Zhang C, Cheng Y, Geng D: The Inhibition of ERK Activation Mediates the Protection of Necrostatin-1 on Glutamate Toxicity in HT-22 Cells. Neurotox Res 2013, 24:64-70.

27. Hallé $M$, Tribout-Jover P, Lanteigne A, Boulais J, St-Jean JR, Jodoin R, Girouard M, Constantin F, Migneault A, Renaud F, et al: Methods to monitor monocytes-mediated amyloid-beta uptake and phagocytosis in the context of adjuvanted immunotherapies. $J$ Immunol Methods 2015, 424:64-79.

28.Zuroff L, Daley D, Black KL, Koronyo-Hamaoui M: Clearance of cerebral Abeta in Alzheimer's disease: reassessing the role of microglia and monocytes. Cell Mol Life Sci 2017, 74.2167-2201.

29.Udan ML, Ajit D, Crouse NR, Nichols MR: Toll-like receptors 2 and 4 mediate Abeta(1-42) activation of the innate immune response in a human monocytic cell line. J Neurochem 2008, 104:524-533.

30.Crouse NR, Ajit D, Udan MLD, Nichols MR: Oligomeric amyloid- $\beta(1-42)$ induces THP-1 human monocyte adhesion and maturation. Brain Res 2009, 1254:109-119.

31.Gordon S, Taylor PR: Monocyte and macrophage heterogeneity. Nat Rev Immunol 2005, 5:953-964.

32.McLean FH, Campbell FM, Sergi D, Grant C, Morris AC, Hay EA, MacKenzie A, Mayer CD, Langston RF, Williams LM: Early and reversible changes to the hippocampal proteome in mice on a high-fat diet. Nutr Metab 2019, 16.

33. Hanisch U, Kettenmann H: Microglia: active sensor and versatile effector cells in the normal and pathologic brain. Nat Neurosci 2007, 10:1387-1394.

34.Xiong X, Liu L, Yang Q: Functions and mechanisms of microglia/macrophages in neuroinflammation and neurogenesis after stroke. Prog Neurobio/ 2016, 142.23-44.

35.de Almagro MC, Vucic D: Necroptosis: Pathway diversity and characteristics. Semin Cell Dev Biol2015, 39:56-62.

36.Shan B, Pan H, Najafov A, Yuan J: Necroptosis in development and diseases. Gene Dev 2018, 32:327340.

37.Caccamo A, Branca C, Piras IS, Ferreira E, Huentelman MJ, Liang WS, Readhead B, Dudley JT, Spangenberg EE, Green KN, et al: Necroptosis activation in Alzheimer's disease. Nat Neurosci 2017, 20:1236-1246.

38.Yuan J, Amin P, Ofengeim D: Necroptosis and RIPK1-mediated neuroinflammation in CNS diseases. Nat Rev Neurosci 2019, 20:19-33.

39.Ofengeim D, Mazzitelli S, Ito Y, DeWitt JP, Mifflin L, Zou C, Das S, Adiconis X, Chen H, Zhu H, et al: RIPK1 mediates a disease-associated microglial response in Alzheimer's disease. Proceedings of the 
40.Kanou T, Ohsumi A, Kim H, Chen M, Bai X, Guan Z, Hwang D, Cypel M, Keshavjee S, Liu M: Inhibition of regulated necrosis attenuates receptor-interacting protein kinase 1-mediated ischemia-reperfusion injury after lung transplantation. J Heart Lung Transplant 2018, 37:1261-1270.

41.Jing L, Song F, Liu Z, Li J, Wu B, Fu Z, Jiang J, Chen Z: MLKL-PITPalpha signaling-mediated necroptosis contributes to cisplatin-triggered cell death in lung cancer $A 549$ cells. Cancer Lett 2018, 414:136-146.

42.Arthur JSC, Ley SC: Mitogen-activated protein kinases in innate immunity. Nat Rev Immuno/2013, 13:679-692.

43.Qin S, Yang C, Huang W, Du S, Mai H, Xiao J, Lü T: Sulforaphane attenuates microglia-mediated neuronal necroptosis through down-regulation of MAPK/NF-KB signaling pathways in LPS-activated BV2 microglia. Pharmacol Res 2018, 133:218-235.

44.Kim EK, Choi E: Compromised MAPK signaling in human diseases: an update. Arch Toxico/2015, 89:867-882.

45.Xu M, Yan T, Fan K, Wang M, Qi Y, Xiao F, Bi K, Jia Y: Polysaccharide of Schisandra Chinensis Fructus ameliorates cognitive decline in a mouse model of Alzheimer's disease. J Ethnopharmacol 2019, 237:354-365.

46.Fao L, Mota SI, Rego AC: Shaping the Nrf2-ARE-related pathways in Alzheimer's and Parkinson's diseases. Ageing Res Rev 2019, 54.

47.Mincheva-Tasheva S, Soler RM: NF-KB Signaling Pathways. The Neuroscientist 2013, 19:175-194.

48.Alvarez SE, Harikumar KB, Hait NC, Allegood J, Strub GM, Kim EY, Maceyka M, Jiang H, Luo C, Kordula T, et al: Sphingosine-1-phosphate is a missing cofactor for the E3 ubiquitin ligase TRAF2. Nature 2010, 465:1084-1088.

49.Festjens N, Vanden Berghe T, Cornelis S, Vandenabeele P: RIP1, a kinase on the crossroads of a cell's decision to live or die. Cell Death Differ 2007, 14:400-410.

50.Zhang M, Li J, Geng R, Ge W, Zhou Y, Zhang C, Cheng Y, Geng D: The Inhibition of ERK Activation Mediates the Protection of Necrostatin-1 on Glutamate Toxicity in HT-22 Cells. Neurotox Res 2013, 24:64-70.

\section{Figures}




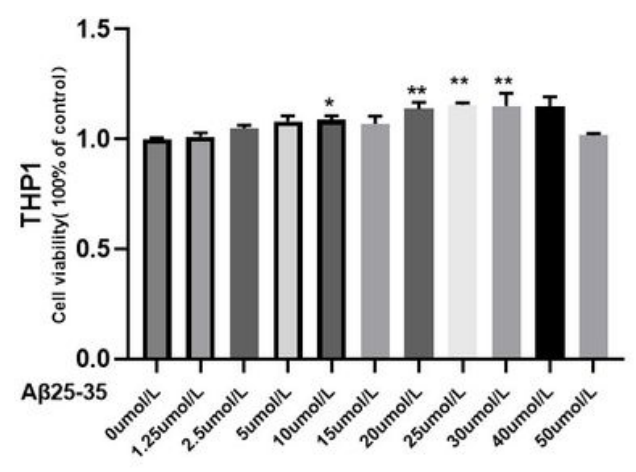

Fig. 1A 1d

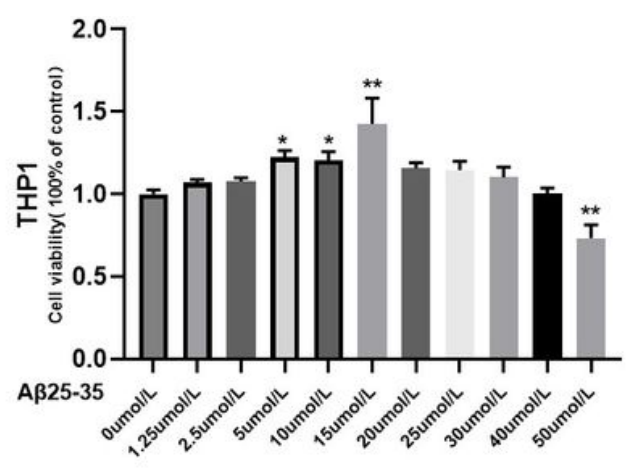

Fig. 1B 3d

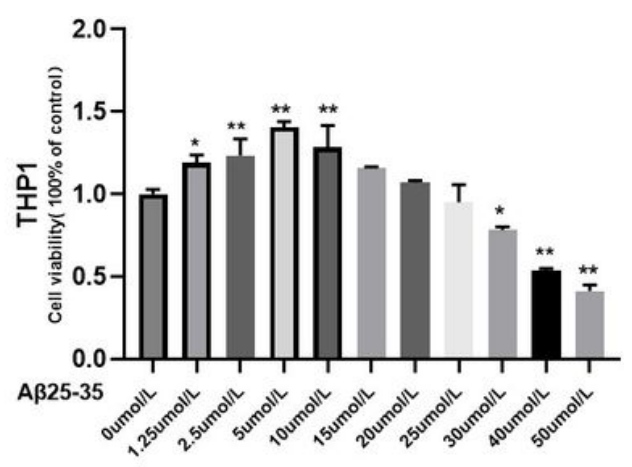

Fig. $1 \mathrm{C} 5 \mathrm{~d}$

Figure 1

THP-1 cell viability following treatment with a concentration gradient of $A \beta 25-35$, with different stimulus

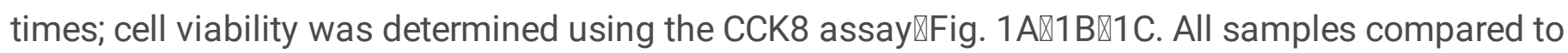
control $\left(0 \mu \mathrm{M}\right.$ AB25-35); data are represented as averages \pm S.D. * $P<0.05 \nabla^{* *} P<0.01$

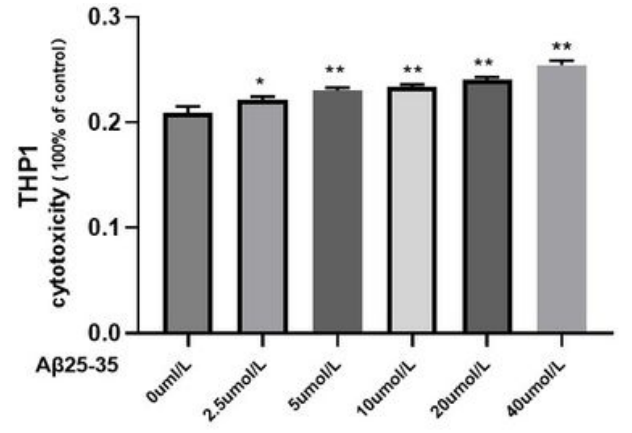

Fig.2A 1d

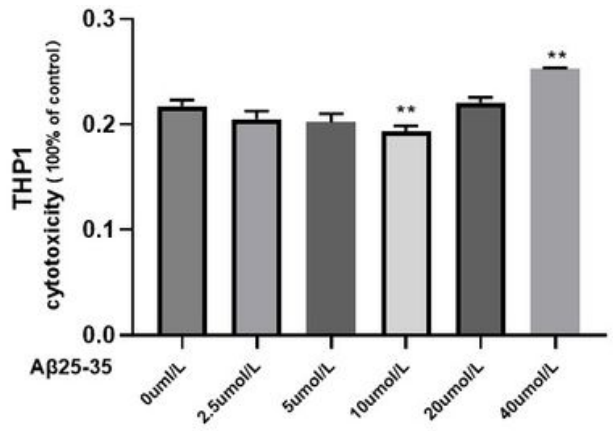

Fig.2B 3d

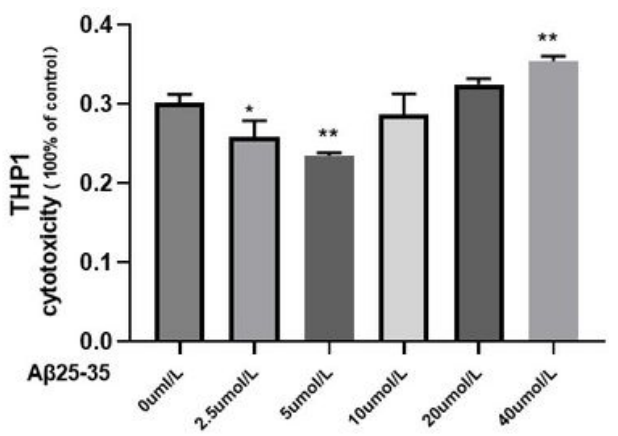

Fig.2C $5 d$

Figure 2

Cytotoxicity was determined using an $\mathrm{LDH}$ release assay, Fig. 2A囚2B $₫ 2 \mathrm{C}$. All samples compared to

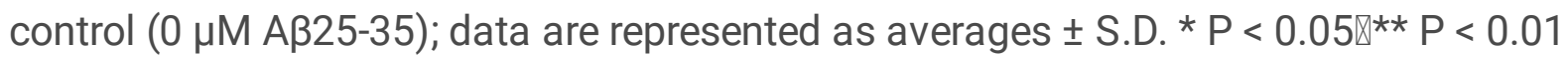



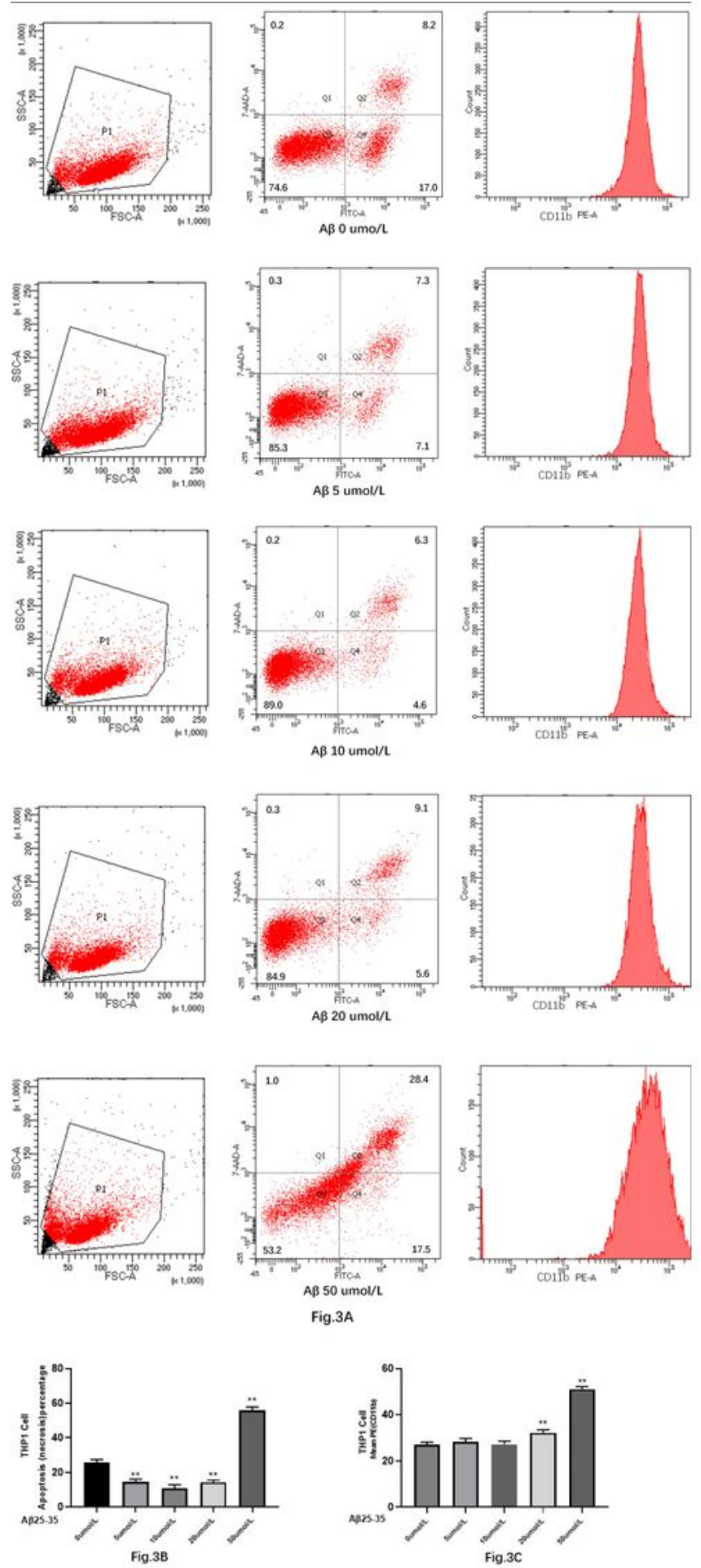

Figure 3

THP1 cells activity treated with A $25-35$ whether the apoptosis (necrosis) and differentiation of THP1 cells is involved, after THP1 cells was treated with Aß25-35 for 3 days, Annexin v-fitc, 7AAD and antigen CD11b (as a surface marker for THP1 cells differentiation were used for flow cytometry analysis. Fig 3A: Normal cells (Q3), Early apoptotic cells (Q4), Late apoptotic / necrosis cell (Q2), CD11b PE-A (cell 
expression after differentiation). The statistical results shown as Fig 3B 3C. Data are presented as mean \pm S.D. Compared with Control group (Aß25-35 OuM), * $P<0.05 \nabla^{* *} \mathrm{P}<0.01$

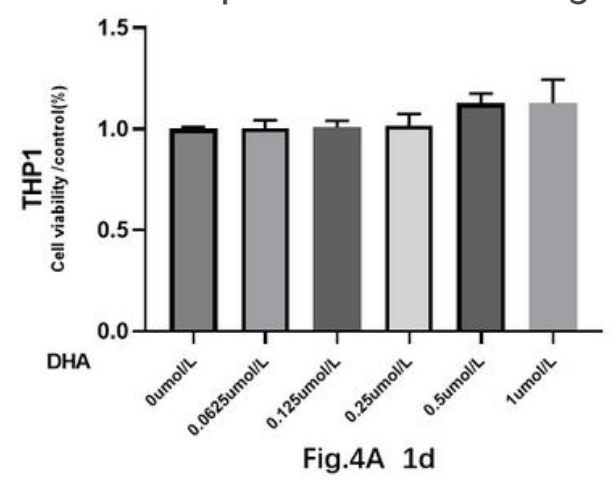

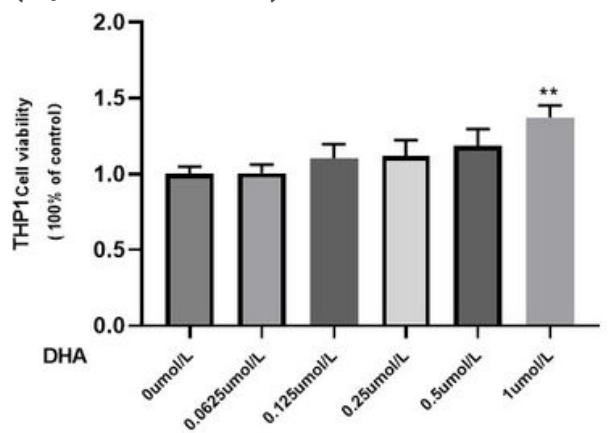

Fig.4B 3d

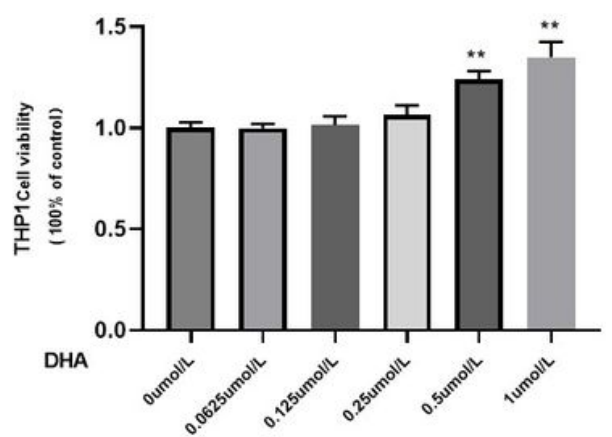

Fig. $4 \mathrm{C}$ d

Figure 4

Effect of DHA on viability of THP-1 cells. DHA was not cytotoxic to THP-1 cells at concentrations of up to $1 \mu \mathrm{M}$. THP- 1 cells were treated with varying concentrations $(0.0625-1 \mu \mathrm{M})$ of DHA for $1 \mathrm{~d}, 3 \mathrm{~d}$, and $5 \mathrm{~d}$. Data are represented as averages \pm S.D. as a percentage of the control group, ${ }^{*} P<0.05 \nabla^{\star *} P<0.01$.

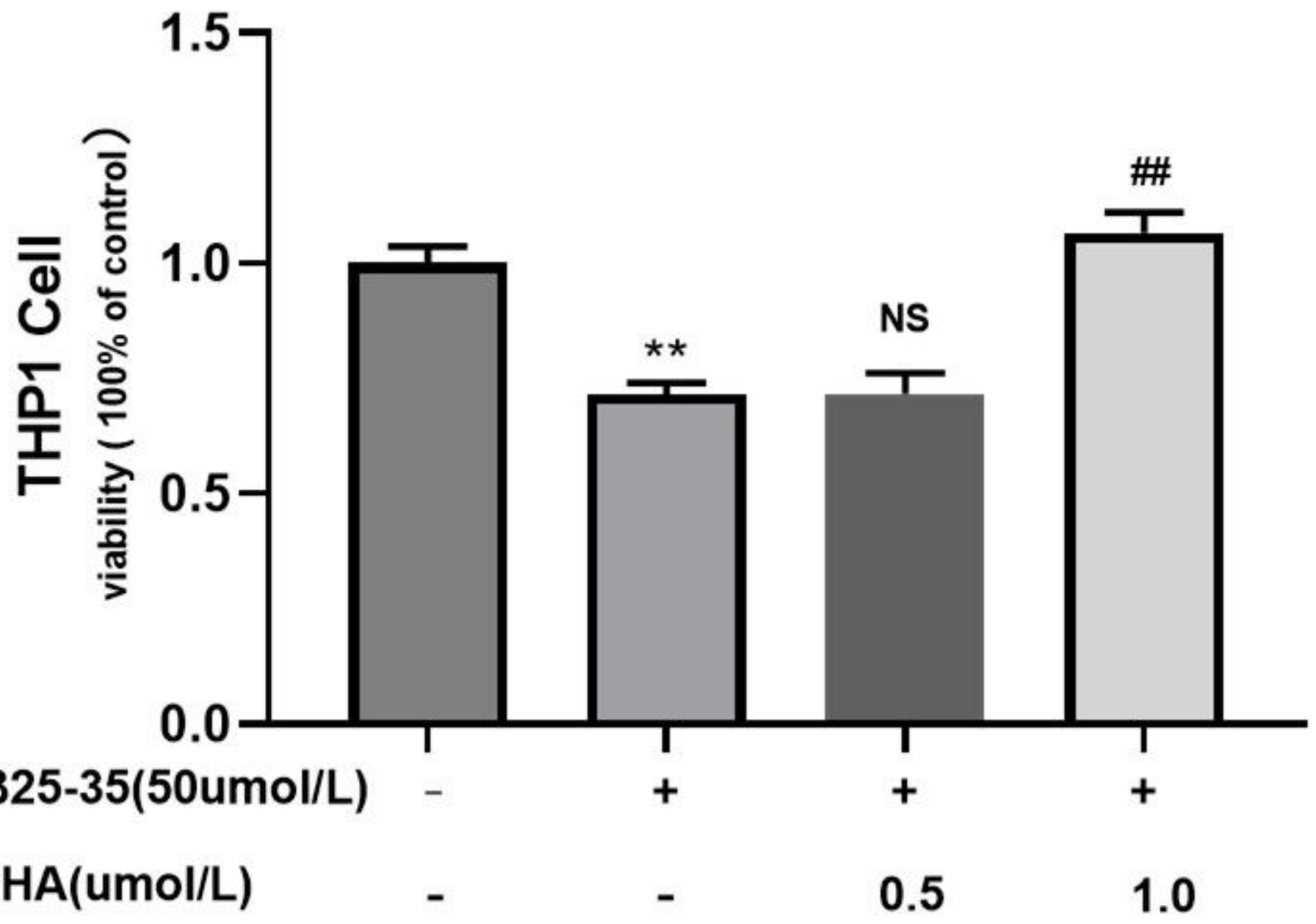

Fig.5

Figure 5 
Effect of DHA pre-treatment on viability of THP-1 cells treated with Aß25-35. The viability of THP-1 cells was analyzed after cultures were pre-treated with DHA $(0.5,1 \mu \mathrm{M})$ in RPMI 1640 with $0 \%$ FBS for $24 \mathrm{~h}$. followed by $50 \mu \mathrm{M}$ A $25-35$ treatment for $3 \mathrm{~d}$. Cell viability was determined using the CCK8 assay. Data are represented as averages \pm S.D. as a percentage of the control group. ${ }^{*} p<0.05$ and ${ }^{* *} p<0.01$, compared to $0 \mu \mathrm{M} \mathrm{A \beta 25-35}$ alone; \#p $<0.05$ and \#\#p <0.01, compared to $50 \mu \mathrm{M} A \beta 25-35$.

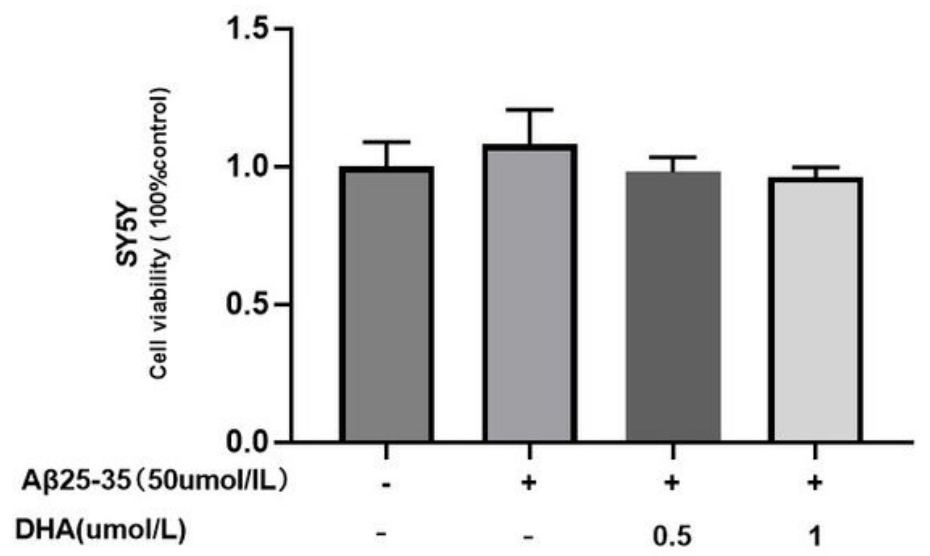

Fig.6A 1d

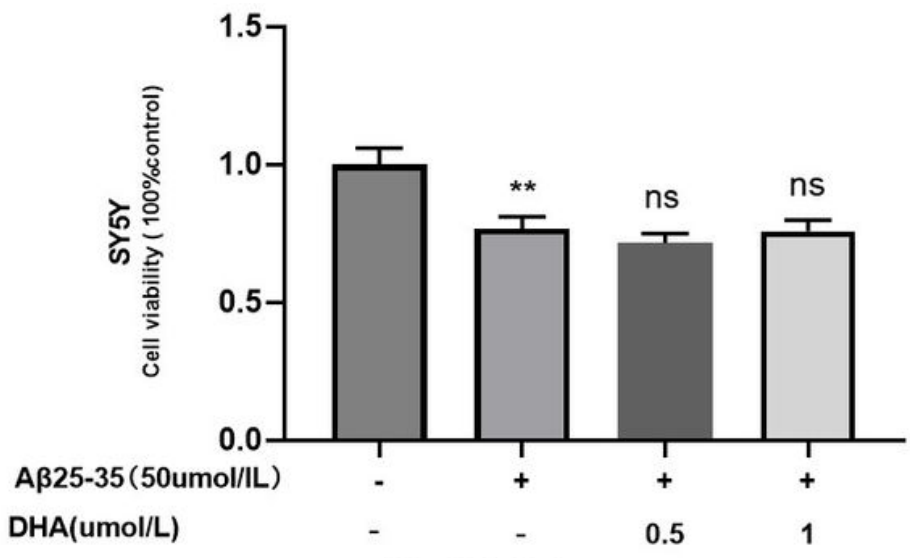

Fig.6B 3d

\section{Figure 6}

Treatment with low concentrations of DHA did not inhibit A 3 -induced activation of neurons and SY5Y cells. Following pre-treatment with or without low concentrations $(0.5,1 \mu \mathrm{M})$ of DHA in RPMI 1640 with $0 \%$ FBS for $24 \mathrm{~h}$, and subsequent treatment with $50 \mu \mathrm{M} \mathrm{A \beta 25-35}$ for $1 \mathrm{~d}$ and $3 \mathrm{~d}$, viability of neurons and SY5Y was determined using the CCK8 assay. Data are represented as averages \pm S.D. as a percentage of the control group. ${ }^{*} p<0.05$ and ${ }^{* *} p<0.01$, compared to $0 \mu \mathrm{M} A \beta 25-35$ alone. $\# p<0.05, \# \# p<0.01$, compared to $50 \mu \mathrm{M}$ A $25-35$.

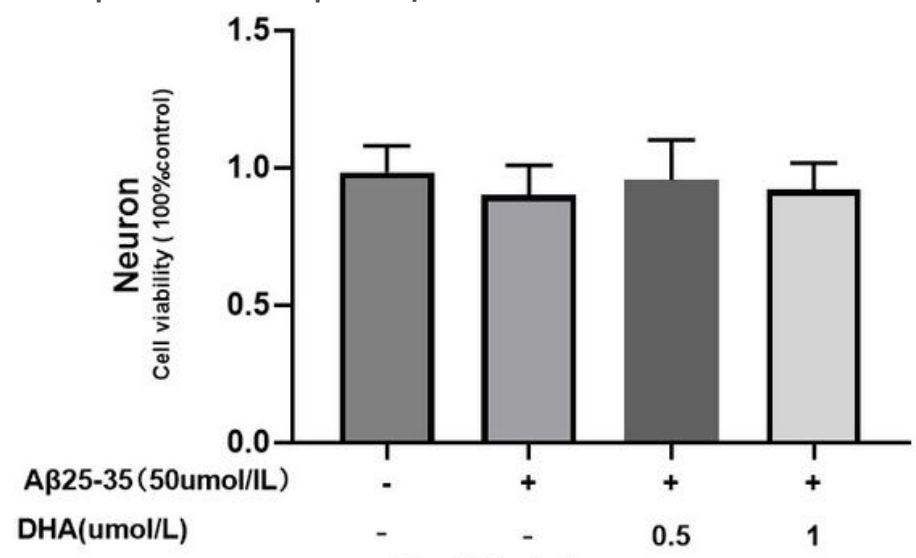

Fig.7A 1d

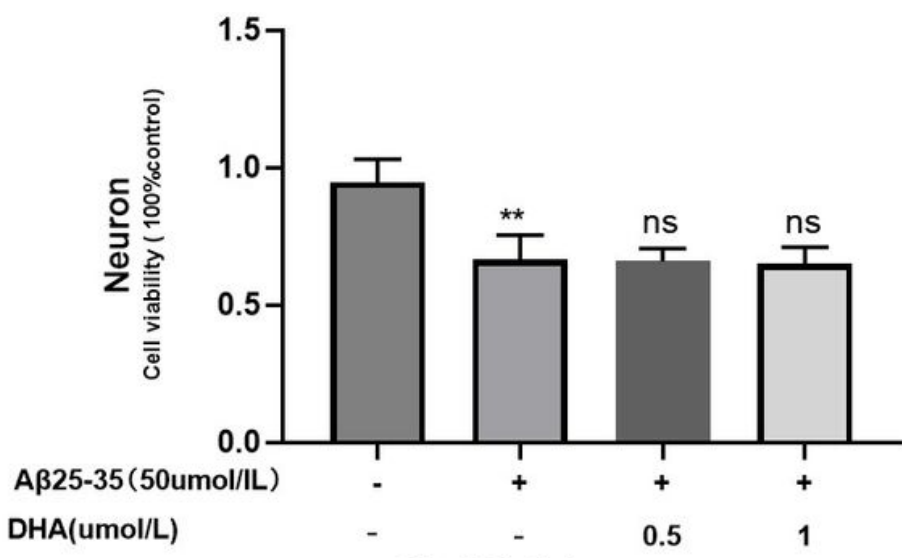

Fig.7B 3d

\section{Figure 7}

Treatment with low concentrations of DHA did not inhibit A 3 -induced activation of neurons and SY $5 Y$ cells. Following pre-treatment with or without low concentrations $(0.5,1 \mu \mathrm{M})$ of DHA in RPMI 1640 with $0 \%$ FBS for $24 \mathrm{~h}$, and subsequent treatment with $50 \mu \mathrm{M} \mathrm{A \beta 25-35}$ for $1 \mathrm{~d}$ and $3 \mathrm{~d}$, viability of neurons and SY5Y was determined using the CCK8 assay. Data are represented as averages \pm S.D. as a percentage of 
the control group. ${ }^{*} p<0.05$ and ${ }^{* *} p<0.01$, compared to $0 \mu \mathrm{M} A \beta 25-35$ alone. $\# p<0.05, \# \# p<0.01$, compared to $50 \mu \mathrm{M}$ A $25-35$.

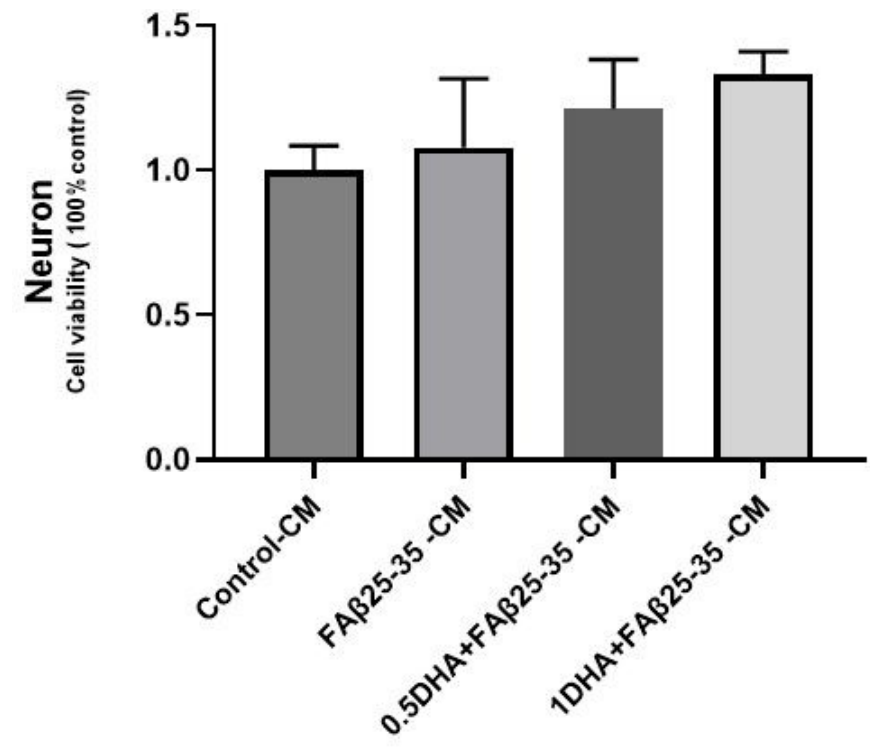

Fig.8A 3d

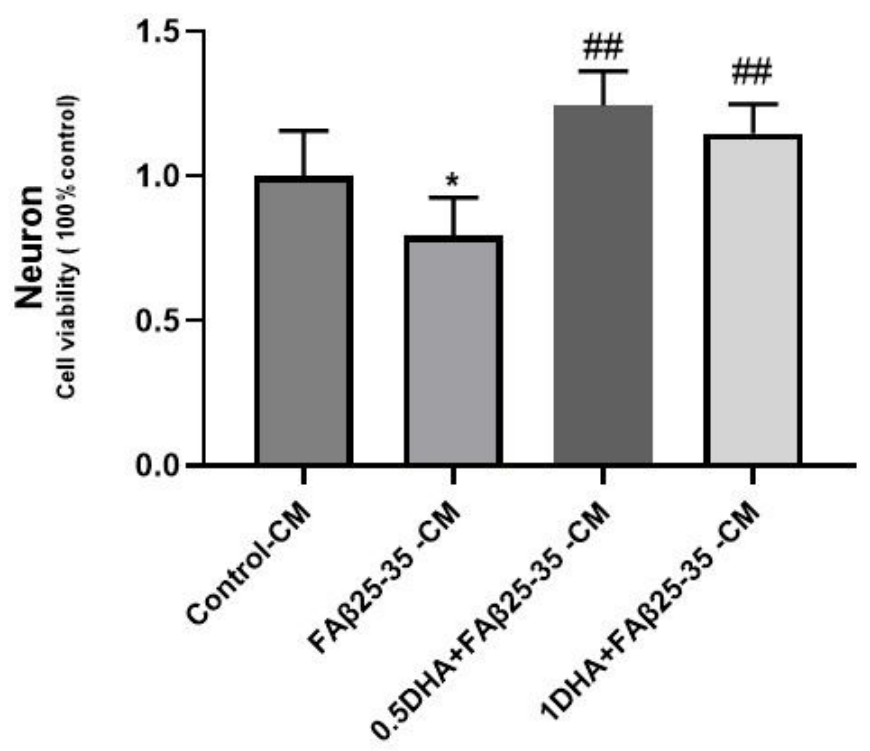

Fig.8B 5d

Figure 8

DHA indirectly suppresses THP-1 cell-mediated neuronal activation. THP-1 cells were pre-treated with or without various concentrations of DHA in RPMI 1640 with $0 \%$ FBS for $24 \mathrm{~h}$, followed by $50 \mu \mathrm{M} \mathrm{A \beta 25-35}$ treatment for 3. CM from each THP-1 treatment group was collected and used to stimulate neurons for 3 or $5 \mathrm{~d}$. Cell viability was determined using the CCK8 assay. Data are represented as averages \pm S.D. as a percentage of the control group. ${ }^{*} p<0.05$ and ${ }^{* *} p<0.01$, compared to control-CM alone. $\# p<0.05$ and $\# \# p<0.01$, compared to $A \beta-C M$. 


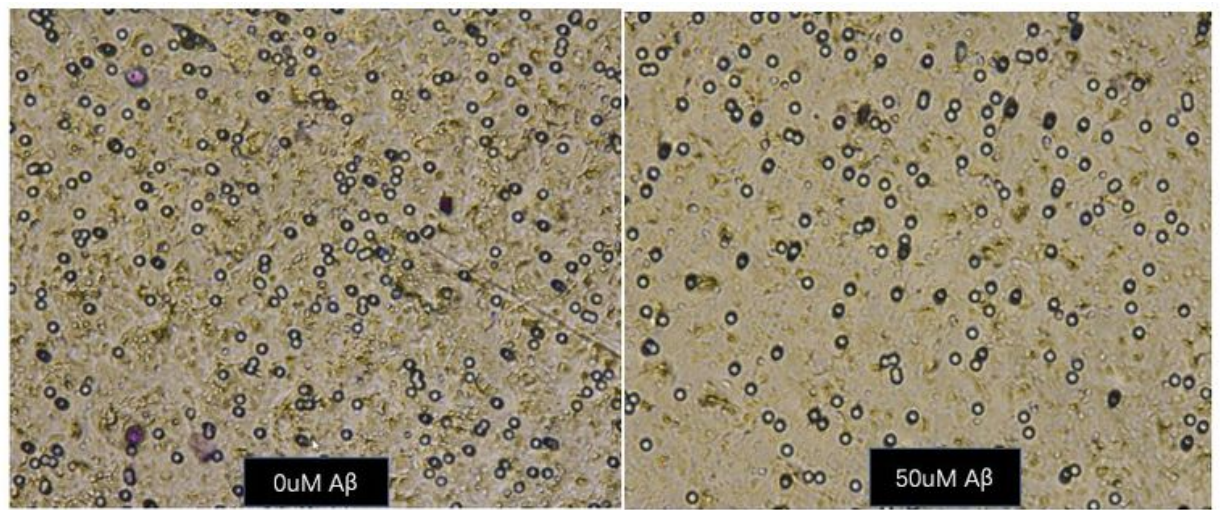

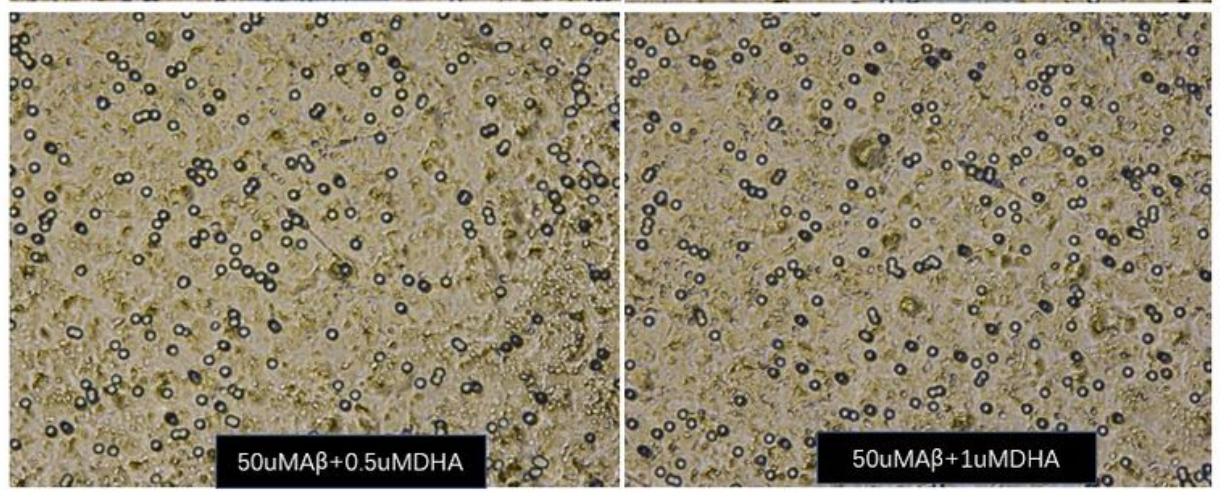

Fig.9A

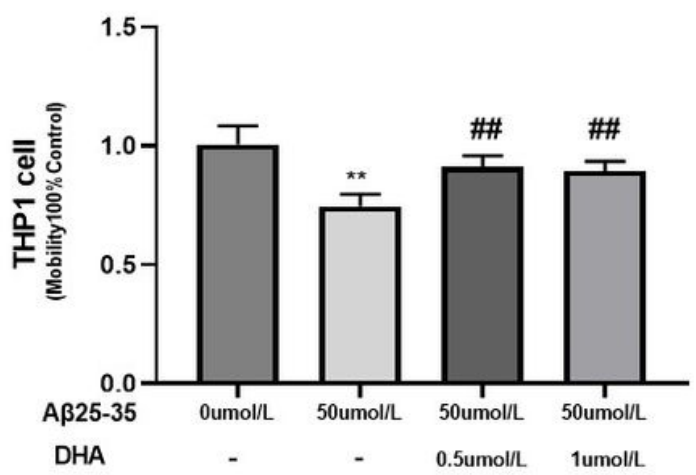

Fig.9B

\section{Figure 9}

DHA pre-treatment inhibits the anti-migratory effect exerted by A $25-35$ on THP-1 monocytes. THP-1 cells were pre-treated with or without low concentrations $(0.5,1 \mu \mathrm{M})$ of DHA in RPMI 1640 with $0 \%$ FBS for $24 \mathrm{~h}$, followed by $50 \mu \mathrm{M}$ Aß25-35 treatment for 3 days. A transwell system was used to test the migratory ability of THP-1 cells after $12 \mathrm{~h}$ from different treatment groups, Cell counting was carried out using a microscope (100X). Data are represented as averages \pm S.D. as a percentage of the control group. ${ }^{*} \mathrm{p}<0.05$ and ${ }^{* * \mathrm{p}}<0.01$, compared to $0 \mu \mathrm{M} \mathrm{A \beta 25-35}$ alone. $\# \mathrm{p}<0.05$ and \#\#p $<0.01$, compared to $50 \mu \mathrm{M}$ A $325-35$. 
TNF- $\alpha$

IL-6

IL-1 $\beta$

GAPDH
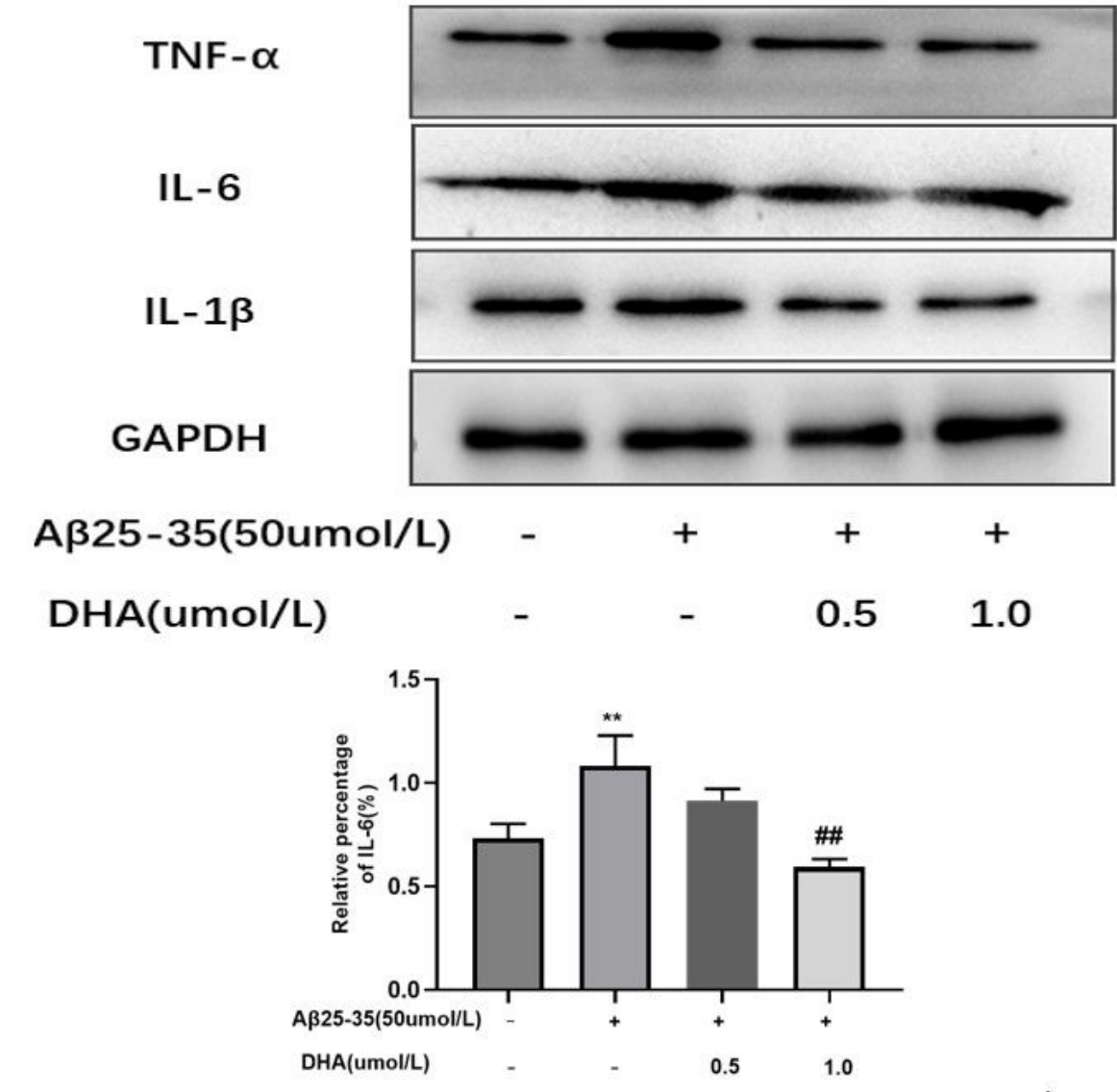

Fig. 10
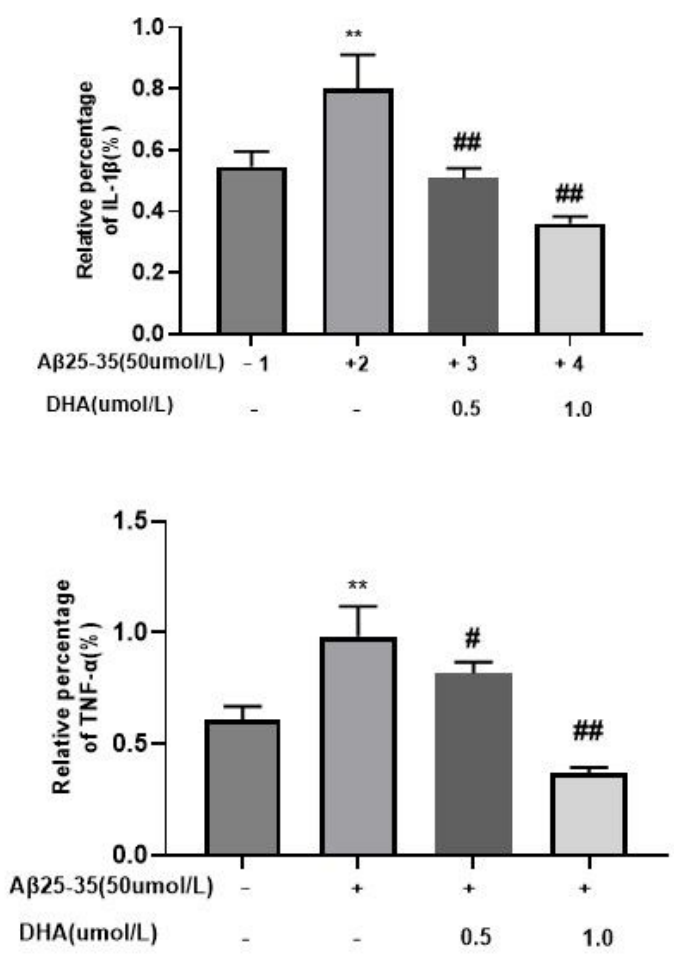

Figure 10

DHA treatment has an inhibitory effect on expression of pro-inflammatory cytokines in A $\beta$-stimulated THP-1 cells. THP-1 cells were pretreated with or without varying concentrations of DHA in RPMI 1640 with $0 \%$ FBS for 1 day prior to incubation with $50 \mu \mathrm{M}$ A 225-35 for another 3 days. Western blot analysis of protein expression of TNF-a, IL-1 $\beta$ and IL-6, normalized to GAPDH. Data are represented as averages \pm S.D. ${ }^{*} p<0.05$ and ${ }^{* \star} p<0.01$, compared to $0 \mu \mathrm{M}$ Aß25-35 alone. $\# p<0.05$ and $\# \# p<0.01$, compared to 50 $\mu \mathrm{M} A \beta 25-35$. 
MLKL

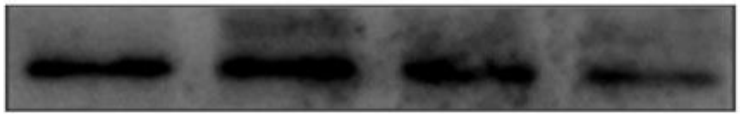

RIPK3

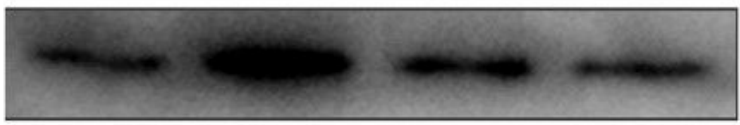

RIPK1

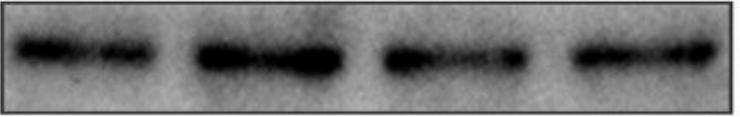

GAPDH
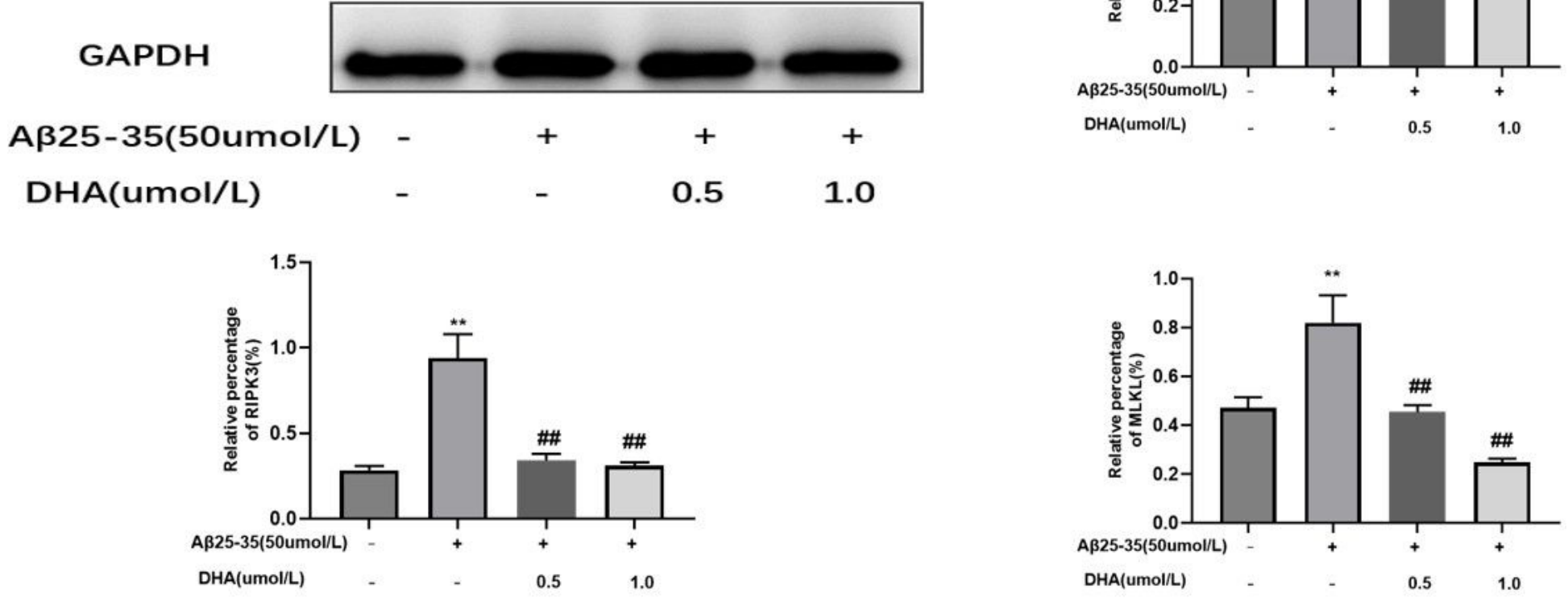

Fig. 11

\section{Figure 11}

DHA treatment inhibits A $25-35$-induced necroptosis of THP-1 monocytes. THP-1 cells were pretreated with or without varying concentrations of DHA in RPMI 1640 with 0\% FBS for 1 day prior to incubation with $50 \mu \mathrm{M}$ Aß25-35 for another 3 days. Western blot analysis of protein expression of RIPK1, RIPK3 and MLKL, normalized to GAPDH. Data are represented as averages \pm S.D. as a percentage of the control group. ${ }^{*} p<0.05$ and ${ }^{* *} p<0.01$, compared to $0 \mu \mathrm{M} A \beta 25-35$ alone. $\# p<0.05$ and $\# \# p<0.01$, compared to $50 \mu \mathrm{M} \mathrm{A \beta 25-35.}$ 


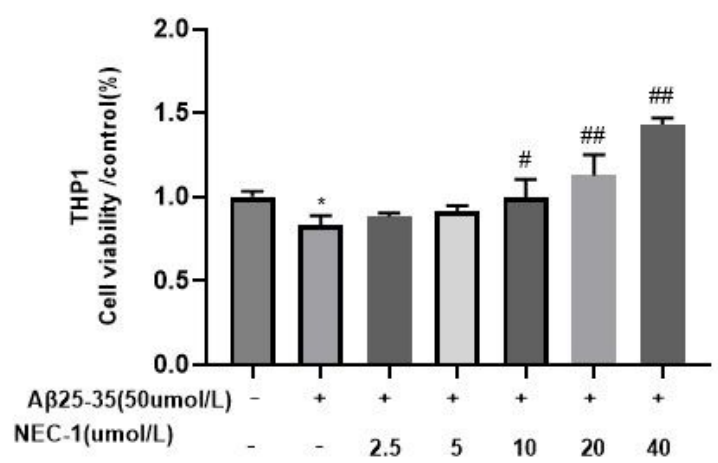

Fig.12A

RIPK3

GAPDH

Aß25-35(50umol/L) $\mathrm{DHA}(1 \mathrm{umol} / \mathrm{L})$

NEC-1 (10umol/L)
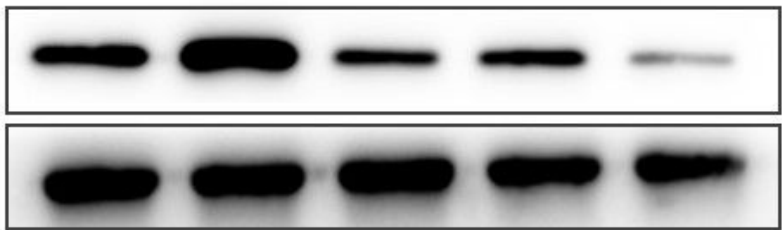

$+$

$+$

$+$

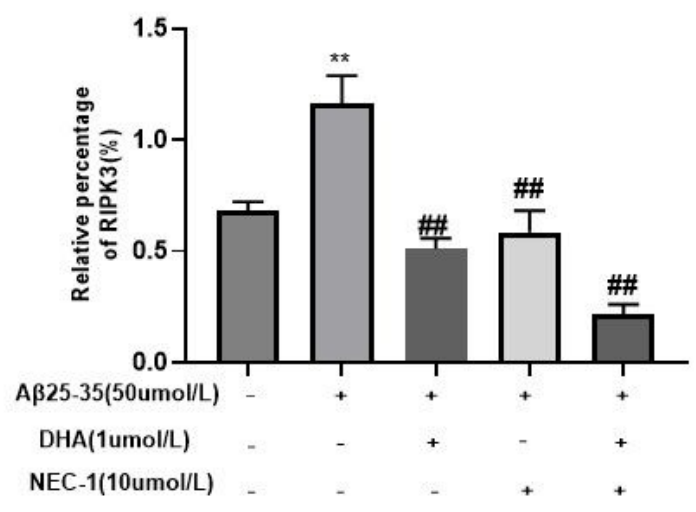

Fig. $12 \mathrm{C}$

\section{Figure 12}

DHA treatment attenuates A $325-35$-induced necroptosis in THP-1 monocytes via the RIPK1/RIPK3 signaling pathway. THP-1 cells were pre-treated with or without various concentrations of NEC-1 in RPMI 1640 with $0 \%$ FBS for $24 \mathrm{~h}$, followed by $50 \mu \mathrm{M}$ Aß25-35 stimulation for $3 \mathrm{~d}$; cell viability was determined using the CCK8 assay (Fig. 12A). THP-1 cells were pretreated with or without NEC-1 and DHA in RPMI 1640 with $0 \%$ FBS for $24 \mathrm{~h}$, followed by $50 \mu \mathrm{M}$ Aß25-35 stimulation for $3 \mathrm{~d}$; Western blotting analysis was

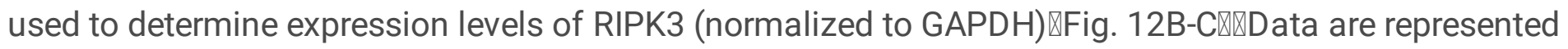
as averages \pm SD. as a percentage of the control group. ${ }^{*} p<0.05$ and ${ }^{* *} p<0.01$, compared to $0 \mu \mathrm{M} A \beta 25$ 35 alone. $\# p<0.05$ and \#\#p <0.01, compared to $50 \mu \mathrm{M} A \beta 25-35$. 

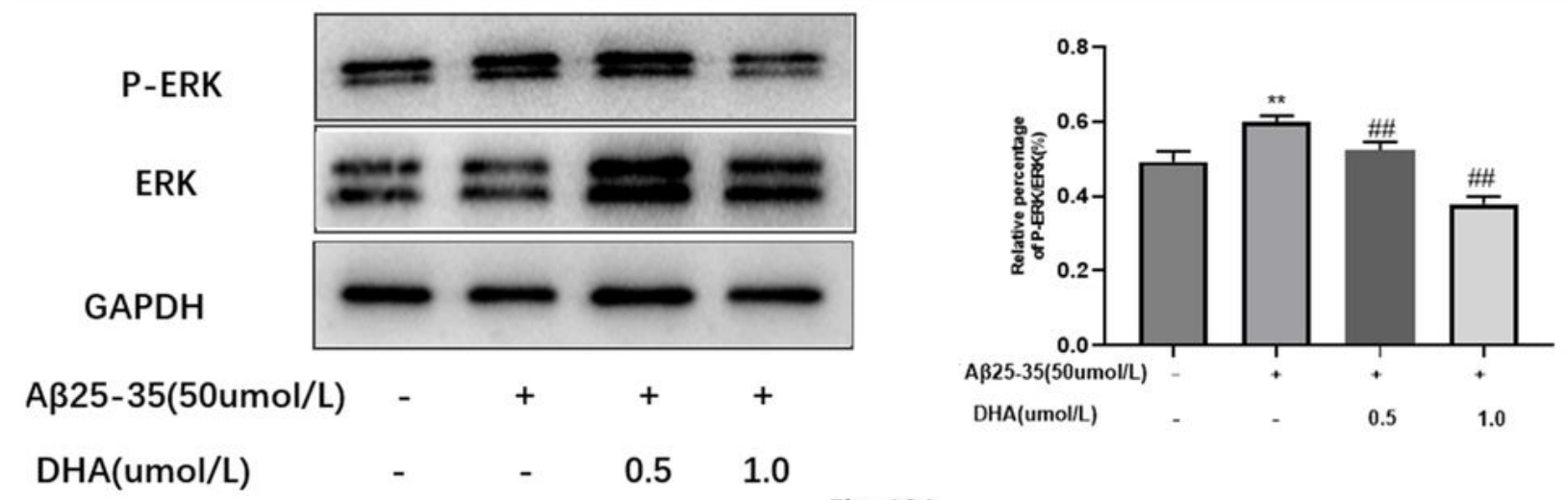

Fig. 13A

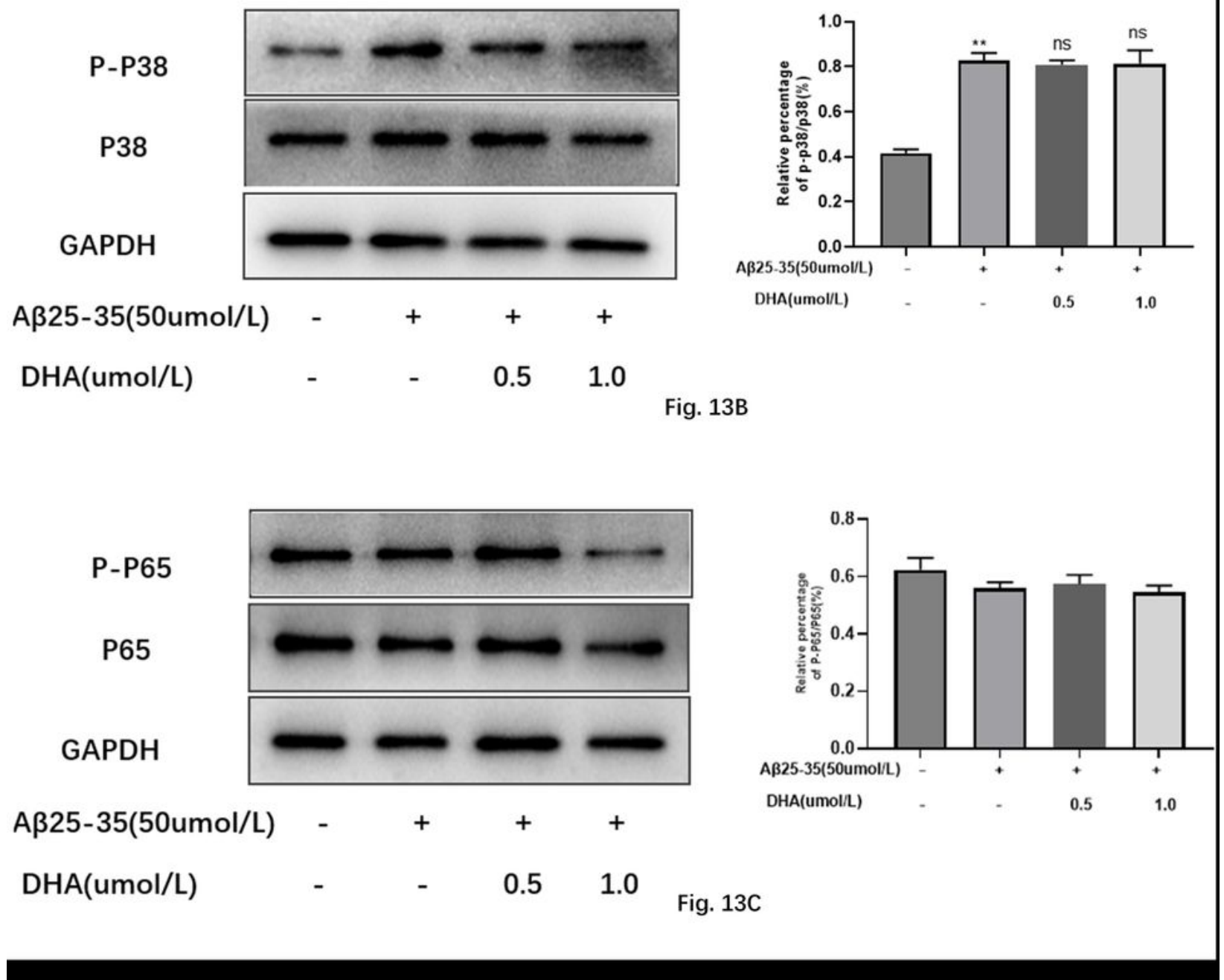

\section{Figure 13}

DHA suppresses the ERK1/2 signaling pathway induced by A $325-35$ in THP-1 cells, but not the p38 or NF-kB/p65 signaling pathways. THP-1 cells were pretreated with or without varying concentrations of DHA in RPMI 1640 with 0\% FBS for 1 day prior to incubation with $50 \mu \mathrm{M}$ A $325-35$ for another 3 days. The phosphorylation status of ERK1/2 (A), p38 (B), and p65 (C) were determined by Western blot analysis. 
Data are represented as averages $\pm S D,{ }^{*} p<0.05$ and ${ }^{* \star} p<0.01$, compared to $0 \mu \mathrm{M} A \beta 25-35$ alone. \#p $<0.05$ and \#\#p $<0.01$, compared to $50 \mu \mathrm{M}$ Aß25-35.
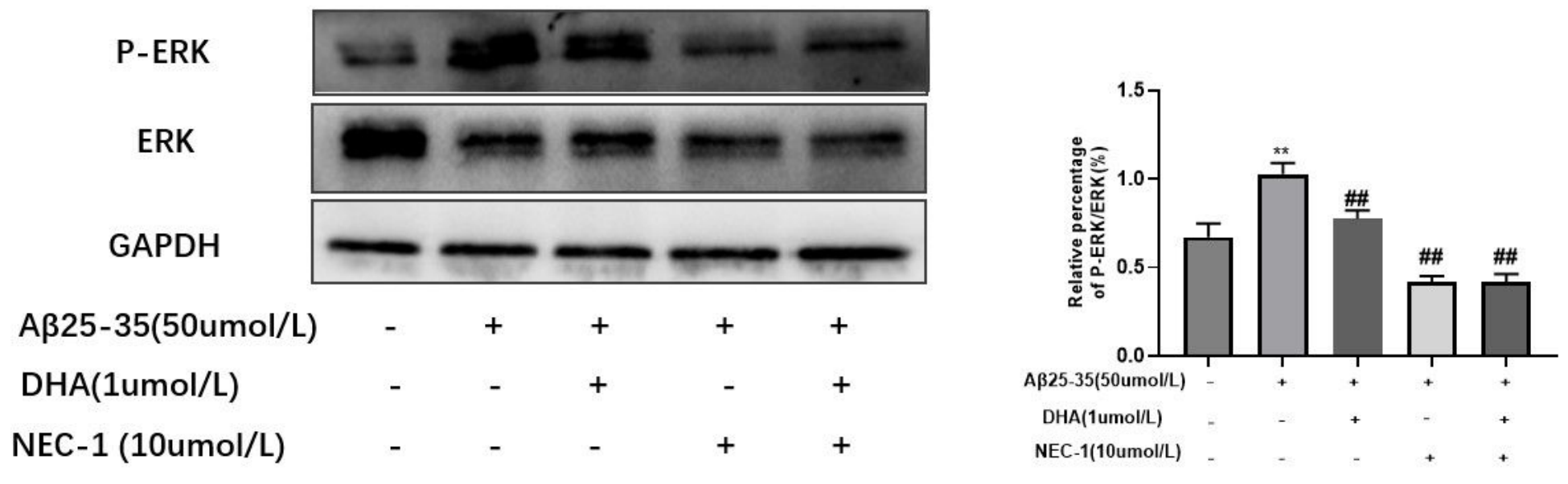

Fig. 14

\section{Figure 14}

DHA treatment inhibits ERK1/2 phosphorylation via RIPK1 in THP-1 cells treated with Aß25-35. THP-1 cells were pre-treated with or without NEC-1 and DHA in RPMI 1640 with $0 \%$ FBS for 24 h, followed by 50 $\mu \mathrm{M}$ A $25-35$ treatment for $3 \mathrm{~d}$. Western blotting was used to determine the phosphorylation status of ERK1/2. Data are represented as averages $\pm S D, * p<0.05$ and $* * p<0.01$, compared to $0 \mu M A \beta 25-35$ alone. \#p $<0.05$ and \#\#p $<0.01$, compared to $50 \mu \mathrm{M} A \beta 25-35$. 